\title{
Income redistribution in the European Union
}

\author{
Silvia Avram ${ }^{1 *}$, Horacio Levy ${ }^{2}$ and Holly Sutherland ${ }^{1}$
}

\author{
* Correspondence: \\ savram@essex.ac.uk \\ 'ISER, University of Essex, Wivenhoe \\ Park, CO4 3SQ Colchester, UK \\ Full list of author information is \\ available at the end of the article
}

\begin{abstract}
We explore the redistributive effects of taxes and benefits in the 27 member states of the European Union (EU) using EUROMOD, the tax-benefit microsimulation model for the EU. As well as describing redistributive effects in aggregate, we assess and compare the effectiveness of eight individual types of policy in reducing income disparities. We derive results for the 27 members of the EU using policies in effect in 2010 and present them for each country separately as well as for the EU as a whole. JEL codes: D31, H24, I38.

Keywords: Redistribution; European Union; Microsimulation; Tax-benefit systems
\end{abstract}

\section{Introduction}

The relationship between the tax-benefit system and the distribution of income has been the focus of longstanding scholarly work (Hicks and Swank 1984; Myles 1984). In particular, the welfare state literature has examined the link between welfare state characteristics and inequality and/or redistribution (Korpi 1989; Esping-Andersen 1990; Castles and Mitchell 1992; Korpi and Palme 1998; Brady 2005). This strand of research has primarily used broad macro-level indicators such as social expenditure as a share of GDP to characterize welfare states. More recently, taking advantage of the availability of micro-data, studies have sought to go into more detail and quantify the redistributive effect of the various components of the tax-benefit systems, a key aspect of the performance of welfare systems that macro data are unable to address. Along with many national studies, several studies have taken on a comparative perspective making use primarily of the Luxembourg Income Study (Mahler and Jesuit 2006; Lambert et al. 2010; Wang et al. 2012) or the EU-SILC (Fuest et al. 2010; Jara and Tumino 2013).

This paper describes the redistributive effects of the systems of direct taxes and cash benefits of 27 member states of the European Union (EU). It is the first such analysis making use of the 27 country version of EUROMOD, the tax-benefit microsimulation model for the EU. International comparisons of redistribution that go beyond the use of model family analysis have tended to focus on particular parts of the tax-benefit system (e.g.Wagstaff and van Doorslaer 2001) or, as described above, make use of data from the Luxembourg Income Study (see also Atkinson et al. 1995; OECD 2011). The latter source is particularly useful if the focus is on long-term trends and not on the detailed workings of up-to-date policy systems. In this paper our focus is on recent (2010) tax-benefit systems which are broken down into detailed components. 
In carrying out our analyses, we rely on micro-simulation techniques to measure several of our income components. In particular, we micro-simulate taxes, social insurance contributions, means-tested benefits, as well as several non-means tested categories of payment ${ }^{1}$. Although the redistributive impact of taxes and benefits may be assessed directly, using the observed values of these income components, we believe microsimulating them has a series of advantages. First, use of a comprehensive microsimulation tool such as EUROMOD allows us to examine benefit transfers at a much more fine-grained level than is possible using SILC micro-data alone. Moreover, since EUROMOD simulates each individual policy, we are able to use our own classification of benefits. This allows us to be much more accurate in our analyses ${ }^{2}$. Second, the use of micro-simulation techniques allows us to disentangle three elements of the income tax system: schedule, allowances and credits. To our knowledge, there is no European comparative micro-data that can make this type of information available. Third, by using micro-simulation we potentially improve on the measurement of some types of transfers that are known to be relatively poorly captured in surveys (such as for example means-tested benefits) ${ }^{3}$. Fourth, micro-simulation allows us to look at recent policies, in this case 2010. Bourguignon and Spadaro (2006) and Figari et al. (2015, forthcoming) provide comprehensive overviews of the ways microsimulation can be used to inform policy analysis.

Examples of previous analysis of redistributive effects using microsimulation at national level include Piketty and Saez (2007) for US federal income taxes and Decoster and Van Camp (2001) for Belgian direct and indirect taxes. EUROMOD has previously been used for comparative analysis of redistributive effects by Immervoll et al. (2006), covering the EU-15 and Paulus et al. (2009) covering 19 countries. In common with most such studies our analysis assesses tax liabilities and benefit payments in terms of their direct impact on household resources. This provides only a partial measure of how transfers between households and governments affect incomes (Boadway and Keen 2000) and this needs to be kept in mind when interpreting results and comparing them across countries. On the one hand, taxes and benefits have an influence on pre tax-benefit market incomes (and economic welfare) which is not captured by looking at the amounts of taxes and benefits alone (Plotnick 1984; Bergh 2005). On the other hand, in-kind transfers (to individual households or provided collectively) represent a significant portion of the resources transferred from governments to households (Paulus et al. 2010; OECD 2011).

We measure incomes and inequality at a particular point in time. The analysis is therefore static and does not attempt to measure the distribution of lifetime incomes or separate the "intra-personal" and "inter-personal" components of cross-sectional inequality. This point is relevant because some of the tax-benefit instruments analysed here (for ex: pensions and other contingency- or insurance-based benefits as well as the taxes earmarked to finance them) are largely designed to redistribute across the life-cycle rather than across individuals. However, using EUROMOD we are able to distinguish these "life-cycle" components from those designed to redistribute from the current rich to the current poor.

In addition, our analysis decomposes the effects of direct taxes not only into income tax and social insurance contributions, but also breaks down the redistributive effects of income taxes into those due to personal allowances, tax credits and the rate structure 
(or schedule). This is similar to previous work for a selection of countries using EUROMOD (Verbist 2004) which focussed on the implications of each component for the progressivity of income taxes.

The remainder of this paper is organised as follows. The following section describes the data, our simulation strategy as well as our measures of inequality and redistribution. Section 3 contains our main results. After examining the relative size of the tax-benefit systems as well as its components in the 27 countries, we turn to measures of redistribution. We find that public pensions together with tax schedules are the most important redistributive elements in all countries. Similarly to Fuest et al. (2010) we do not find that Central and European tax-benefit systems have peculiar features distinguishing them as a group from the other Member States.

\section{Methods}

\subsection{EUROMOD}

To evaluate the redistributive effect of national tax-benefit systems we make use of EUROMOD, the tax-benefit microsimulation model for the European Union (Lietz and Mantovani 2007; Sutherland and Figari 2013). EUROMOD relies on micro-data representative of the household population of each EU member state to compute tax liabilities and benefit entitlements corresponding to each of the 27 tax-benefit systems existent in the EU. Based on a common framework - which applies the same methods and approaches both in the construction of its input databases and in the calculation of taxes and benefits of each country - EUROMOD is a unique tool for international comparative research on the effects of taxes and benefits, and their reforms, on the distribution and redistribution of income.

EUROMOD simulates policy instruments in detail. They can be classified into four types of policies, namely social insurance contributions, direct income taxes and their sub-components, means-tested benefits and some types of non-means-tested benefits. With some exceptions, pensions and other contributory benefits are not simulated due to absence of information on contribution histories in the input dataset. Instead, the values of these income variables are taken directly from the data.

Simulations are carried out using individual and household information from the European Union-Survey of Income and Living Conditions (EU-SILC) ${ }^{4}$. The User Database (UDB) contains the demographic, labour market and income characteristics of a representative sample of households from each EU Member State. In some cases, we are able to make use of supplementary information from the national version of SILC. Information about the datasets used for each of the 27 countries included in the analyses is available in Table 1. While in principle SILC provides a readymade source of comparable information across $27 \mathrm{EU}$ member states, some issues remain and the quality and comparability of our results are to some extent reliant on the quality and comparability of SILC data (see Figari et al. (2007); Jara and Sutherland (2013)).

In this paper, we focus on the policies in effect on the $30^{\text {th }}$ of June 2010. Simulations are carried out using data collected in the year 2008 with income information referring to the previous year - the only exceptions are France (data collected in 2007), Malta (data collected in 2009), and the UK (data collected in 2008/2009 and income refers 
Table 1 Euromod databases

\begin{tabular}{|c|c|c|}
\hline Country & & Input data \\
\hline Belgium & $\mathrm{BE}$ & EU-SILC version $2008-2$ \\
\hline Bulgaria & BG & EU-SILC version 2008-2 (+additional national variables) \\
\hline Czech Republic & $C Z$ & EU-SILC version 2008-2 (+additional national variables) \\
\hline Denmark & DK & EU-SILC version 2008-1 \\
\hline Germany & $\mathrm{DE}$ & EU-SILC version 2008-2 \\
\hline Estonia & $\mathrm{EE}$ & EU-SILC version 2008-2 \\
\hline Ireland & $\mathrm{IE}$ & EU-SILC version 2008-2 \\
\hline Greece & $\mathrm{EL}$ & National SILC 2008 \\
\hline Spain & ES & National SILC 2008 \\
\hline France & $\mathrm{FR}$ & EU-SILC version 2007-3 \\
\hline Italy & IT & National SILC 2008 \\
\hline Cyprus & CY & EU-SILC version 2008-2 \\
\hline Latvia & LV & EU-SILC version 2008-3 \\
\hline Lithuania & $\mathrm{LT}$ & EU-SILC version 2008-2 (+additional national variables) \\
\hline Luxembourg & LU & EU SILC 2008-2 (+additional national variables \\
\hline Hungary & $\mathrm{HU}$ & EU-SILC version 2008-2 \\
\hline Malta & MT & EU-SILC version 2009-1 \\
\hline Netherlands & $\mathrm{NL}$ & EU-SILC version 2008-2 \\
\hline Austria & AT & National SILC 2008 \\
\hline Poland & $\mathrm{PL}$ & EU-SILC version 2008-2 (+additional national variables) \\
\hline Portugal & PT & EU-SILC version 2008-2 \\
\hline Romania & $\mathrm{RO}$ & EU-SILC version 2008-2 \\
\hline Slovenia & $\mathrm{SL}$ & EU-SILC version $2008-2$ \\
\hline Slovakia & SK & National SILC 2008 \\
\hline Finland & $\mathrm{Fl}$ & EU-SILC version 2008-2 \\
\hline Sweden & SE & EU-SILC version $2008-2$ \\
\hline United Kingdom & UK & Family Resources Survey 2008/9 \\
\hline
\end{tabular}

Note: Detailed information about how the EUROMOD input datasets have been constructed from the original sources of micro-data may be found in the corresponding Country Reports.

https://www.iser.essex.ac.uk/euromod/resources-for-euromod-users/country-reports.

to the previous month). The discrepancy between the data and simulation time periods is dealt with by adjusting monetary variables in the input dataset. All monetary variables are brought to price levels of the policy simulation year by applying uprating indices that reflect the average evolution of these variables between the income reference period and the year of simulation (in our case from 2007 to 2010). For more information and technical details on each country see the EUROMOD Country Reports ${ }^{5}$.

\subsection{Measurement}

\subsubsection{Measures of inequality, redistribution and progressivity}

In order to measure the effects of taxes and benefits on the income distribution, we use a set of common inequality indicators. The inequality measures used are members of the so-called single parameter Gini (or S-Gini) family (Donaldson and Weymark 1980; Yitzhaki 1983). By choosing the value of an "ethical" parameter $v$, the S-Gini $(S G)$ 
allows different weights $w$ to be put on the contribution of lower versus higher income groups to total inequality ${ }^{6}$ :

$$
S G(v)=\int_{0}^{1} w \cdot(p-L(p)) d p
$$

where

$$
w=v \cdot(v-1) \cdot(1-p)^{v-2}, v>1,
$$

$p$ is the rank of individuals in a population with individual observations ordered in ascending order of income whose inequality is to be measured and $L(p)$ is the Lorenz curve, i.e., the share of total income earned by the poorest $p \cdot 100 \%$. For $v=2$, we have $w=2$ and $S G(v)$ is the standard Gini coefficient of inequality where departures from equality $(p-L(p))$ are weighted equally for all $p$, while $v>2(<2)$ gives more weight to smaller (larger) $p$.

The equalising effect of the tax system can be measured as the difference between S-Gini indices of the pre- and post- tax benefit income distributions, i.e. the Reynolds-Smolensky redistribution index (Reynolds and Smolensky 1977).

$$
R E(v)=S G_{g}(v)-S G_{n}(v)
$$

The overall redistributive effect of the tax benefit system can be decomposed into a vertical redistribution element which captures the extent to which incomes post taxbenefit are more equally redistributed (VE) and re-ranking term (R) that captures the extent to which the ranking of individuals according to income pre and post taxes and benefits differs. The degree of vertical redistribution is reduced by any changes in the ranking of individuals in the pre and after tax-benefit distribution.

$$
R E(2)=V E(2)-R(2)
$$

where

$$
\begin{aligned}
& V E(2)=S G_{g}(2)-C I_{n}(2)=2\left(\int_{0}^{1} p-L_{g}(p) d p-\int_{0}^{1} p-C_{n}(p) d p\right), \\
& R(2)=S G_{n}(2)-C I_{n}(2)=2\left(\int_{0}^{1} p-L_{n}(p) d p-\int_{0}^{1} p-C_{n}(p) d p\right)
\end{aligned}
$$

where $L_{g}(p)$ and $C_{n}(p)$ are, respectively, the Lorenz and concentration curves of income before and after taxes and benefits.

It can be formally shown that the redistributive effect (RE) can be further decomposed as

$$
R E=K \frac{r}{1-r}-R
$$

where

$$
\begin{aligned}
& r=\frac{\left(\mu_{g}-\mu_{n}\right)}{\mu_{g}} \\
& K=2 \int_{0}^{1} p-C_{t}(p) d p-S G_{g}(2)
\end{aligned}
$$


$r$ is the size of taxes and benefits expressed as the relative difference between mean income before and after taxes and benefits $\mu_{\mathrm{g}}$ and $\mu_{n}$ (i.e. the average 'tax' rate imposed by the tax-benefit system), $K$ is the Kakwani progressivity index (Kakwani 1977) and $d$ is the above-mentioned re-ranking term measuring by how much vertical redistribution is reduced as a result of differences in the ordering of market and disposable incomes (Plotnick 1981; Atkinson 1980). $C_{t}(p)$ and $C_{n}(p)$ are, respectively, the cumulative proportions of total taxes and benefits and disposable incomes at point $p$ where individuals are ordered in terms of market incomes.

Thus, the inequality reducing properties of the fiscal system depend on the size and inequality of the distribution of taxes and benefits, as well as any re-ranking induced by the tax-benefit system. Since the decomposition works analogously for $w \neq 2$, we can derive measures of redistribution $(R E)$ and progressivity $(K)$ using different "ethical" parameters $v$. In this paper, the following three values for $v$ are used: 1.5, 2 and 3.

\subsubsection{Inequality decomposition by source}

In order to show the relative contribution of each source of income to overall income inequality, the Gini coefficient of disposable income can be also decomposed into the weighted sum of the concentration coefficients of its various sources (Lerman and Yitzhaki 1985):

$$
G=\sum_{k=1}^{K} r_{k} C_{k}
$$

$r$ is the share of source $\mathrm{k}$ in disposable income, and $\mathrm{C}_{\mathrm{k}}$ is the concentration coefficient with observations ranked in ascending order of disposable income. The concentration coefficient thus expresses how unequal the income component $\mathrm{k}$ is distributed across disposable income groups. The higher the concentration coefficient $C_{k}$ or the share of the most unequally distributed (or "concentrated") components, the larger the Gini coefficient of disposable income will be.

The effect of a marginal increase in the income source $k\left(\mathrm{M}_{\mathrm{k}}\right)$ on the Gini coefficient of disposable income can be measured as the difference between the contribution of $\mathrm{k}$ to inequality and its share of disposable income. Hence,

$$
M_{k}=\frac{r_{k} C_{k}}{G}-r_{k}
$$

The sign of the effect depends on the sign of $C_{k}$ since $r$ is always positive. This means that if the concentration coefficient from source $k$ is negative, the marginal effect will be negative. Otherwise, the sign will depend on the difference between the concentration coefficient of source $\mathrm{k}$ and the Gini coefficient. If the concentration coefficient of source $\mathrm{k}$ is smaller than the Gini, the marginal effect will be negative; otherwise the effect will be positive ${ }^{7}$.

We calculate standard errors for all our estimates of inequality and redistribution using bootstrap ${ }^{8}$. To avoid making assumptions about the shape of the distribution of our parameters of interest, we use bias corrected confidence intervals where the lower and upper bounds are set to incorporate $95 \%$ of the distribution. 
One must remember that, in practice, there are other possible sources of error in the estimations besides sampling error. Therefore, confidence intervals should not be taken as definitive but as an indication of the accuracy of the estimates.

\subsubsection{Income}

In this analysis we assume that income is equally shared within the household, so that household disposable income can be used as an indicator of the economic well-being of each individual within the household ('within household' incidence is not considered).

Household disposable income is defined as market (original) income plus private transfers and social benefits minus taxes and social contributions, aggregated at the household level. Non-cash benefits are not included. Household disposable incomes are equivalised using the modified OECD equivalence scale.

In analysing the redistributive effect of tax-benefit systems, we distinguish between the following income components:

- original market income: this includes labour income, unearned income such as income generates by assets (including private pensions), and inter-household transfers

- public pension income: this includes pension income from all public statutory pension schemes

- social insurance contributions: these include mandatory contributions paid by employees and self-employed to cover contingencies such as unemployment, sickness, old-age etc.

- means-tested benefits: we include here any benefit whose entitlement rules incorporate conditions referring to individual or household incomes (and assets where relevant and possible); fully refundable tax credits that depend on income/earnings are included in this income component.

- contributory benefits: these include any short-term benefit (i.e. not a pension) the awarding of which depends on previous contributions being paid.

- non-contributory, non-means tested benefits: this is a residual category that includes cash transfers that do not meet one of the criteria above. To maintain consistency, fully refundable tax credits that do not depend on income/earnings are also included in this income concept.

- direct income taxes: this concept incorporates any type of taxes (excluding contributions) paid on any type of household income.

Since direct income taxes are often the result of complex taxation systems, we disaggregate them into three components not all of which are necessarily present in all countries: tax schedules, tax allowances, and tax credits. Tax allowances and tax credits are so-called fiscal benefits and they may be an important channel through which the tax benefit system directs resources towards households. A tax allowance is any type of deduction from initial taxable income that would lower the effective tax base. This includes social insurance contributions whenever they are deductible from the tax base, as well as any tax bands where the tax rate is zero. A tax credit is any type of nonrefundable deduction from the initial tax liability (gross tax). To effect the decomposition we take following approach. First, using EUROMOD, we estimate the gross tax (i.e. before 
any tax credits) payable in the baseline scenario. We then re-calculate gross tax when all tax allowances in the system (including social insurance contributions when deductible, 0 rate bands etc.) are removed, i.e. set to zero. The difference between the gross taxes calculated in the two scenarios provides a measure of the 'value' of tax allowances for each household, i.e. the amount of income each household gains via lower taxes due to the existence of tax allowances. We measure the size of tax schedules as the gross tax that would be payable in the absence of tax allowances. The size of this variable is driven by the tax schedule but also by other elements of the income tax system such as the extent to which various types of incomes are subject to taxation, joint vs. individual taxation, progressivity adjustments etc. In the remainder of the paper we will refer to the tax schedule/taxable base component of the income tax system as "taxes". Finally, tax credits are the difference between gross and net taxes. Refundable tax credits are treated as benefits and thus included in the benefit concepts, not in tax credits, as explained above.

It should be made clear that although the decomposition of direct income taxes into different elements corresponding to schedules, allowances and credits goes a long way towards unpicking the workings on the income tax systems, this decomposition does not cover all the elements of income taxation. Features such as joint versus individual taxation, transferability of tax allowances and credits and progressivity adjustments, while included in the simulation are not directly addressed by our decomposition.

\section{Results}

\subsection{Relative size of tax-benefit systems}

Before looking at the redistributive effects of taxes and benefits, we consider the relative size of the tax benefit system and its components. We define the size of the tax benefit system as the sum of all tax-benefit components, i.e. all pensions, benefits, taxes, tax allowances, tax credits, social insurance contributions, employer contributions taken as a share of household disposable income ${ }^{9}$. Using the aggregate sum of all tax and benefit components as an indicator of system size has both advantages and disadvantages. On the one hand, it can be roughly interpreted as system 'reach'. The larger the share of taxes and benefits, the lower the share of original market incomes and thus the higher the potential for redistribution. On the other hand, the measure incorporates some churning. For example, including the sum of the tax (schedule), tax allowances and tax credits elements will yield considerably larger values of system size compared to including net taxes only, at least in some countries. Similarly, countries that offer higher taxable benefits will appear to have a larger tax-benefit size compared countries that offer lower non-taxable benefits, albeit the effect in disposable income may be exactly the same.

Figure 1 shows the relative sizes of nine types of taxes and benefits. Countries are ranked by the scale of their tax-benefit system calculated as described above. The first thing to notice is that the size of the tax benefit system varies widely among the 27 countries. Thus, taxes and benefit instruments are three times larger in Sweden, the country with the biggest system, compared to Bulgaria where taxes and benefits are smallest as a percentage of disposable income. Secondly, the incorporation of taxes and social insurance contributions (both worker and employers) in the calculation of the tax-benefit size yields very different results from looking at benefits only. For example, 


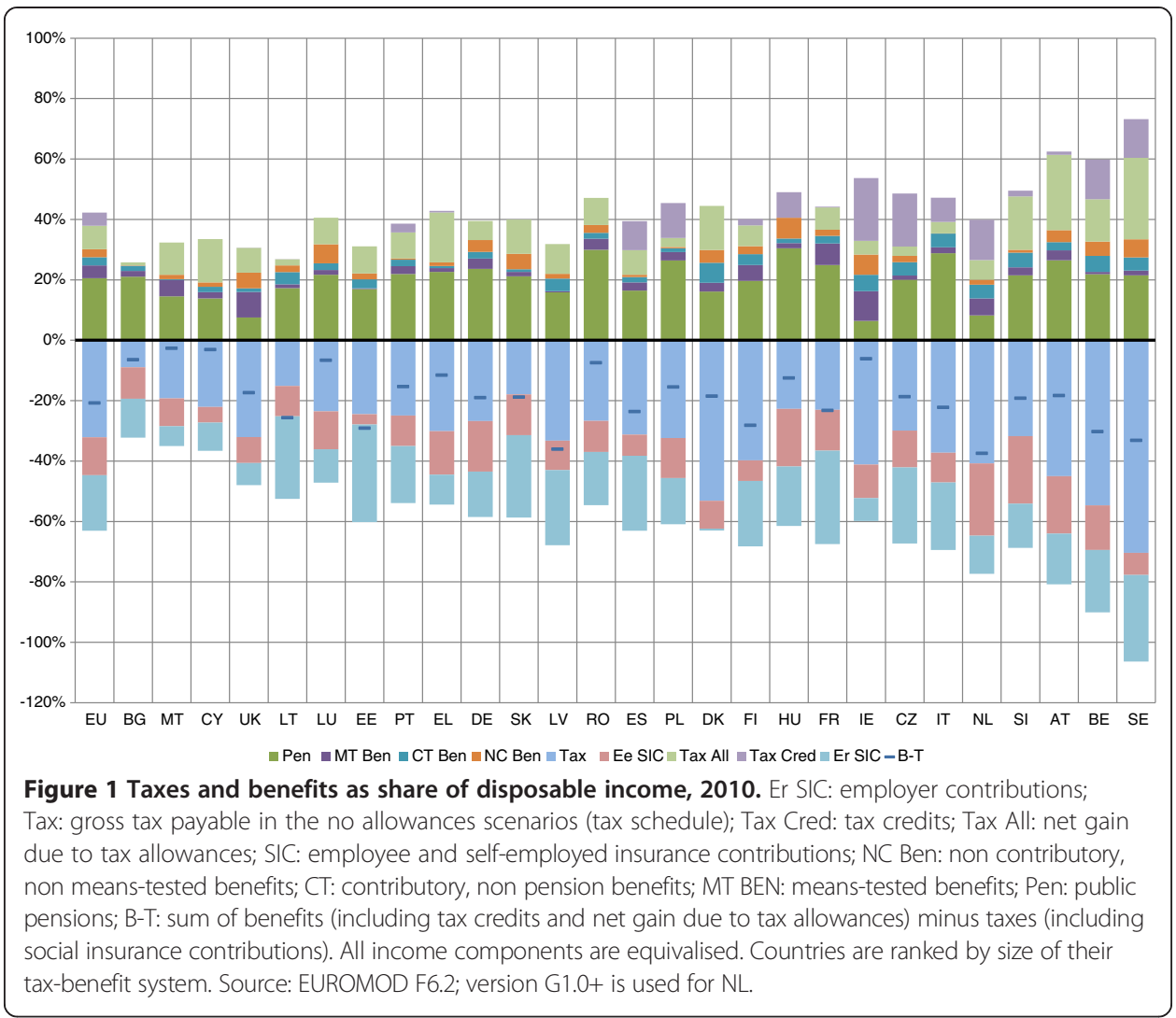

Italy usually categorized as a less developed welfare state (Ferrera 1996) ranks relatively high using our measure.

Not surprisingly, among benefits, pensions are the largest component. They are particularly important in Romania, Hungary and Italy. They are least important in the UK, Ireland and the Netherlands where private and/or occupational pension schemes (here included in original income) feature prominently. With the exception of a few countries -Denmark, Ireland, Netherlands, Belgium and Slovenia - contributory benefits (other than pensions) are a relatively small income component totalling less than $5 \%$ of equivalised disposable income. Similarly, non contributory non means-tested benefits account for between 0 and 7 percent of disposable income. They are most important in Hungary, Ireland, Belgium and Luxembourg. In most countries, means-tested benefits amount to less than $5 \%$ of disposable income. There are some exceptions such as the UK and Ireland where the prevalence of means-testing has been well documented. Other countries where means-tested benefits also play a more prominent role are France, the Netherlands, Malta and Finland.

Contrary to the literature on regime types (Esping-Andersen 1990; Korpi and Palme 1998), there appears to be no systematic relationship between the various types of non-pension benefit instruments. The country-level correlation between the size of means-tested benefits and other non-pension benefits (as a percentage of disposable income) is low and actually positive (0.15). Similarly, there is no systematic pattern linking the relative size of means-tested benefits to that of contributory benefits. The country level correlation between the sizes of these two elements of the tax benefit 
system is 0.03 . However, there appears to be a mild and positive correlation between contributory and non-contributory non means-tested benefits (the country level correlation is 0.33 ) suggesting that countries with higher contributory benefits also have higher non-contributory non-means-tested ones, possibly due to a higher general generosity of the welfare system.

By far the largest component of the tax-benefit system, taxes are also the most significant driver of overall system size variation. When including employee and employer social insurance contributions, taxation ranges between $32 \%$ of disposable income in Bulgaria to $106 \%$ in Sweden. Obviously, the high taxation levels shown in Figure 1 are also due to the separation of tax schedules, tax allowances and tax credits. Part of the income tax liabilities shown in the blue bars above are returned via tax allowances and tax credits $^{10}$. In fact, there is a very close relationship between taxation levels and the use of tax allowance and tax credit instruments ${ }^{11}$. Broadly speaking, countries may be loosely categorised as having either simple and low tax rates systems (Cyprus, Bulgaria) or more complicated higher taxation ones (Denmark, Austria). Essentially, higher initial gross tax liabilities are reduced via tax allowances and tax credits, thus resulting in much lower average tax rates than what the tax schedule alone would suggest. Theoretically, the use of tax allowances and tax credits should provide extra flexibility to adjust the burden on particular groups.

Most countries do use tax allowance and tax credit instruments to fine tune their fiscal regimes. However, the extent to which these types of fiscal tools affect disposable income varies considerably. In some countries such as Sweden, Belgium, Austria, Slovenia or Netherlands tax allowances and tax credits have a larger effect on disposable income than non-pension benefits. Their use is generally much less widespread in the New Member States. Generally, tax allowances are more important than tax credits. The decomposition of net taxes into the tax schedule, tax allowances and tax credits is shown in Figure 2. The tax schedule is clearly the most important determinant of the final amount of net taxes ${ }^{12}$. However, tax allowances and tax credits significantly reduce the initial tax liability. For example, the initial gross tax liability is approximately halved in Sweden, Belgium and Ireland by the use of tax allowances and tax credits.

Worker and employer social insurance contributions amount, on average, to about a third of disposable income. Countries with low contributions include Cyprus, Bulgaria, Malta, the UK and Denmark whereas the burden of contributions is highest in France, Slovakia and Hungary. Employer contributions generally exceed those paid by employees and self-employed although a few countries, notably Denmark, are exceptions.

By and large, countries that tax more are also the countries that make use of more substantial benefit transfers. The country-level correlation between net tax liabilities (incl. employer contributions) and the size of benefit outlays is a moderate -0.41 . When looking at gross tax liabilities (incl. employer contributions) and a wider benefit measure that includes tax allowances and tax credits, the correlation coefficient increases notably to -0.78 . However, part of this increase is explained by the negative relationship between the size of the gross tax schedule. Figure 1 also illustrates the aggregate net effect of the tax benefit system. This effect is negative in all countries meaning that overall, taxes collected exceed benefit outlays. 


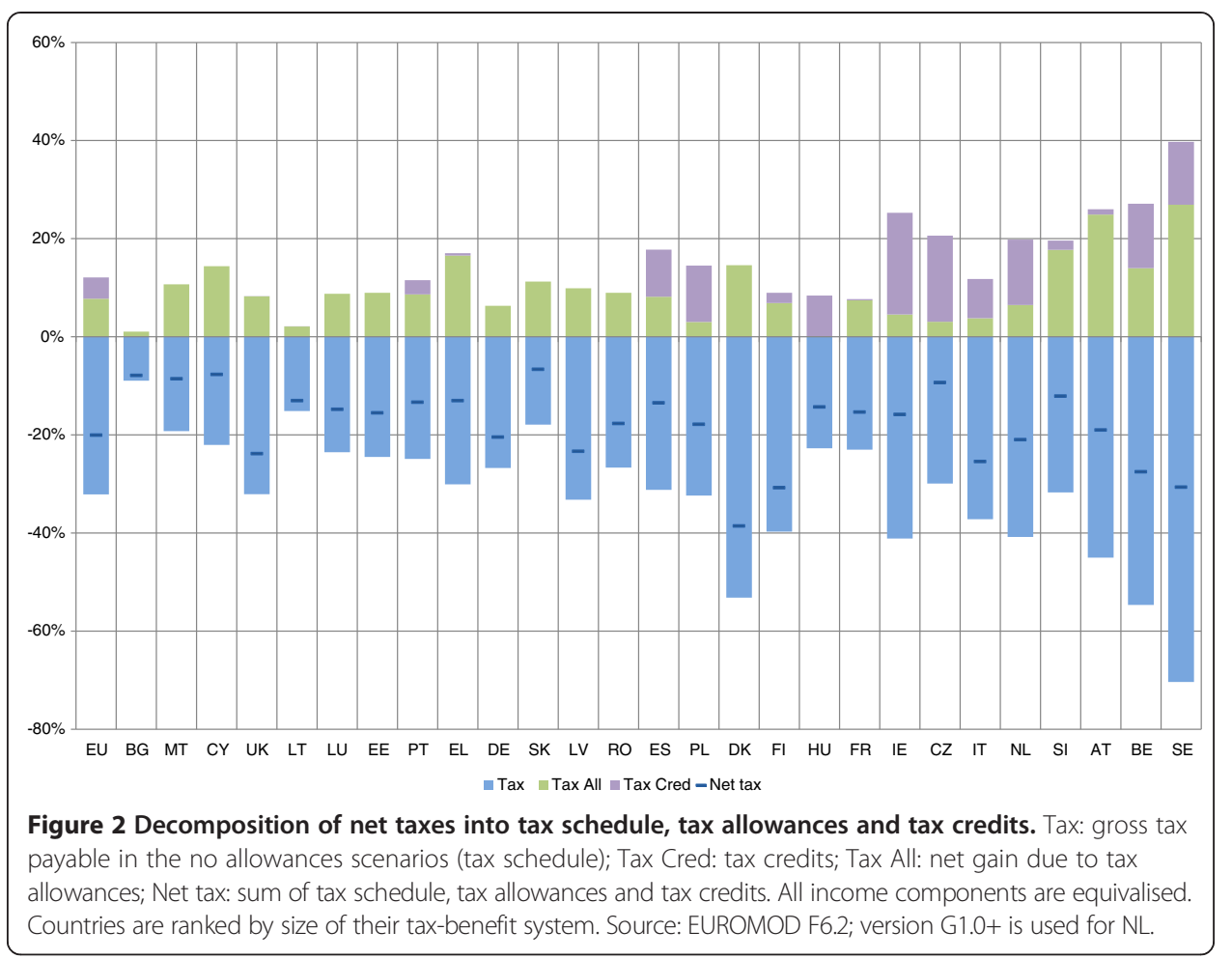

\subsection{Distribution of income components}

To gain a better understanding of how the various components of the tax benefit system affect households along the income distribution, we have repeated the analysis above separately for each quintile of disposable income. Figure 3 presents the relative size of different income components for the bottom quintile. As in Figure 1, countries are ranked by the size of their tax-benefit system.

In all countries the bottom quintile gains from the tax benefit system. This is illustrated in Figure 3 by the positive value of the B-T indicator. Not surprisingly, households in the bottom of the distribution receive more by way of benefits and tax concessions than they pay via direct taxes and social insurance liabilities. However, the magnitude of the gain differs from country to country. Thus, households in the bottom quintile gain most from the tax benefit system in Belgium, Denmark, Finland, Ireland and the UK where their net receipts total around or just above $50 \%$ of their disposable income. Conversely, households in the bottom quintile benefit least from the tax benefit system in Lithuania, Italy, Latvia, Greece and Hungary. In these countries, the net gain of households in the bottom quintile is, on average, less than $20 \%$ of disposable income.

Among benefits, pensions rank high as an income source for the poorest quintile in all 27 countries. They are particularly important in Estonia, Poland, Sweden, Belgium and Denmark where they account for over $40 \%$ of disposable income. As expected, means-tested cash benefits are also an important income source for the bottom quintile especially in countries where means-testing plays a prominent role such as the UK and Ireland. France, the Netherlands, and Romania also have relatively large means-tested income components, accounting for approximately a third of disposable income in the bottom quintile. 


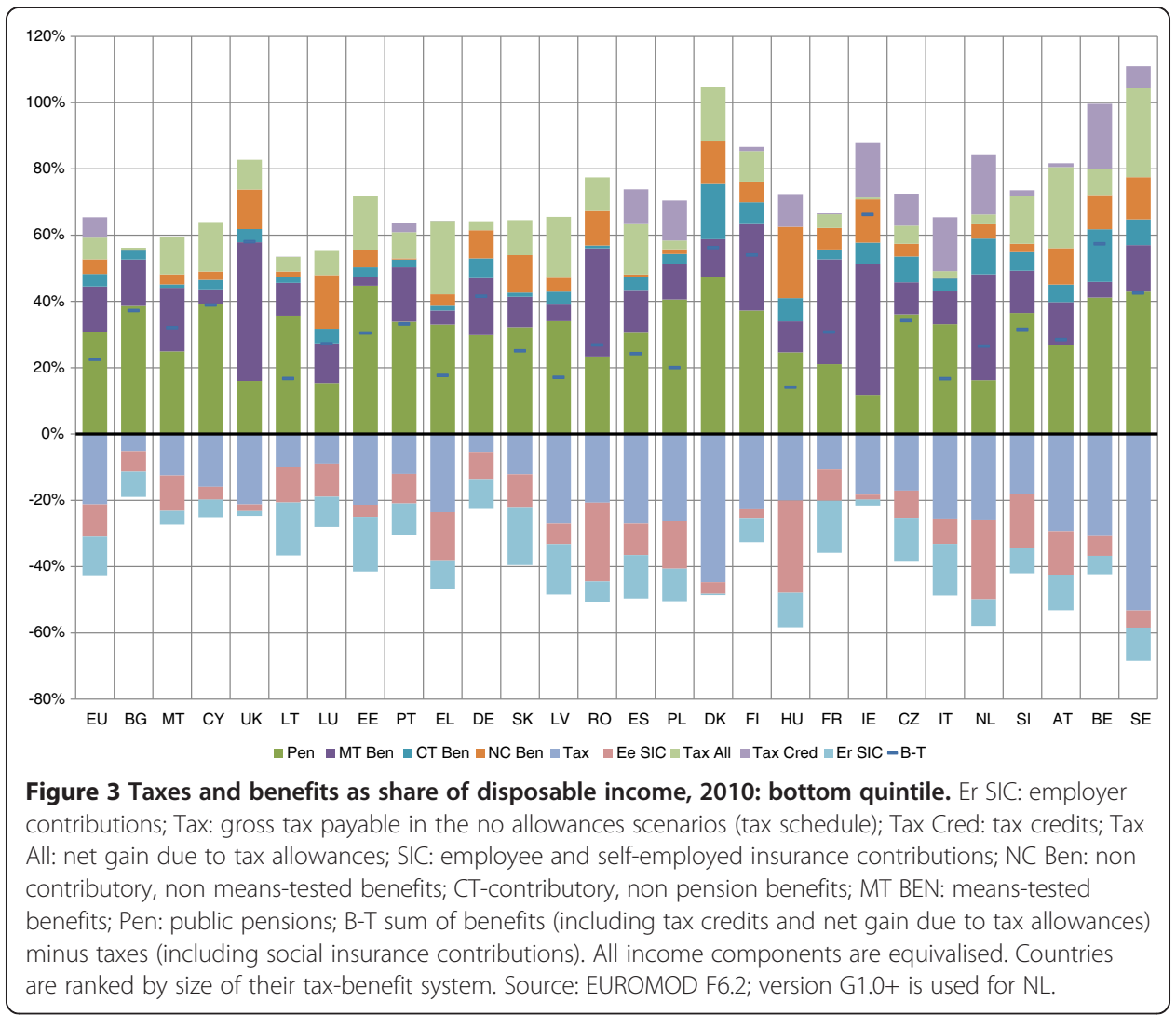

Finally, non-pension and non-means-tested benefits appear to play a less important role for the bottom quintile. Particularly contributory benefits are unlikely to contribute much to incomes in the lowest quintile with a few notable exceptions-Denmark, Netherlands, and Belgium. There is more diversity in the relative size of non meanstested non-contributory benefits. They are clearly very important to households in the bottom quintile in Hungary but also in a few other countries such as Luxembourg, Slovakia, Sweden, Belgium, Ireland, Romania, Denmark, or Austria.

Taxes and social insurance contributions are obviously much lower in the bottom quintile compared to the population as a whole in all 27 countries. In some countries, most notably Bulgaria and Germany but also Luxembourg, households in the bottom quintile pay very little in the way of direct income taxes. Countries where taxation levels on the bottom quintile are higher such as Sweden, Denmark, Belgium or Austria also use tax allowances and tax credits to reduce the final tax liability. Tax allowances play an especially important role in boosting the incomes of the poor in Sweden, Austria and Greece where they account, on average, for more than a fifth of disposable income. This is a somewhat surprising finding considering that tax allowances can be taken advantage of only to the extent that there is enough taxable income. In Austria and Greece, this result can probably be explained by the large share of income households in the bottom quintile derive from market sources (61\% in Austria and 74\% in Greece), income which is usually subject to taxation. In Sweden on the other hand, many of the benefits that go to the bottom quintile are taxable. High taxation of the poor can occur also via high worker contributions. Netherlands, Romania and Hungary 
are the countries that stand out in this respect with worker contributions that amount, on average, to more than $20 \%$ of disposable income.

Relative sizes of different types of taxes and benefits in the top quintile are shown in Figure 4. The most important instrument affecting incomes in the top quintile is clearly direct income taxation. However, the relative size of this instrument varies enormously among the $27 \mathrm{EU}$ countries. It ranges from 11\% in Bulgaria to $78 \%$ in Sweden. As in the case of the general population, higher taxation levels are generally offset by higher tax allowances and tax credits ${ }^{13}$.

On the benefit side, clearly pensions are the most important transfer to the top quintile. Means-tested benefits are virtually unavailable to households in this section of the income distribution. Similarly, non means tested benefits-both contributory and non-contributory, while clearly not zero, make up a very small proportion of disposable income at the top.

The B-T line indicates the overall net gain from the tax benefit system. This indicator is negative for households in the top quintile of the income distribution in every country indicating that richer households contribute more than they take out from the part of the system that we examine. Yet, the size of their contribution is country specific. Generally, countries where the tax benefit system strongly advantages the bottom quintile are also countries where the top loses relatively more. Examples include Finland, Sweden, Netherlands, and Belgium. The reverse is however not true. Countries where the bottom gains relatively less from the tax benefit system are not necessarily imposing a lower burden on the top. For example, in Latvia the difference between benefits and taxes is

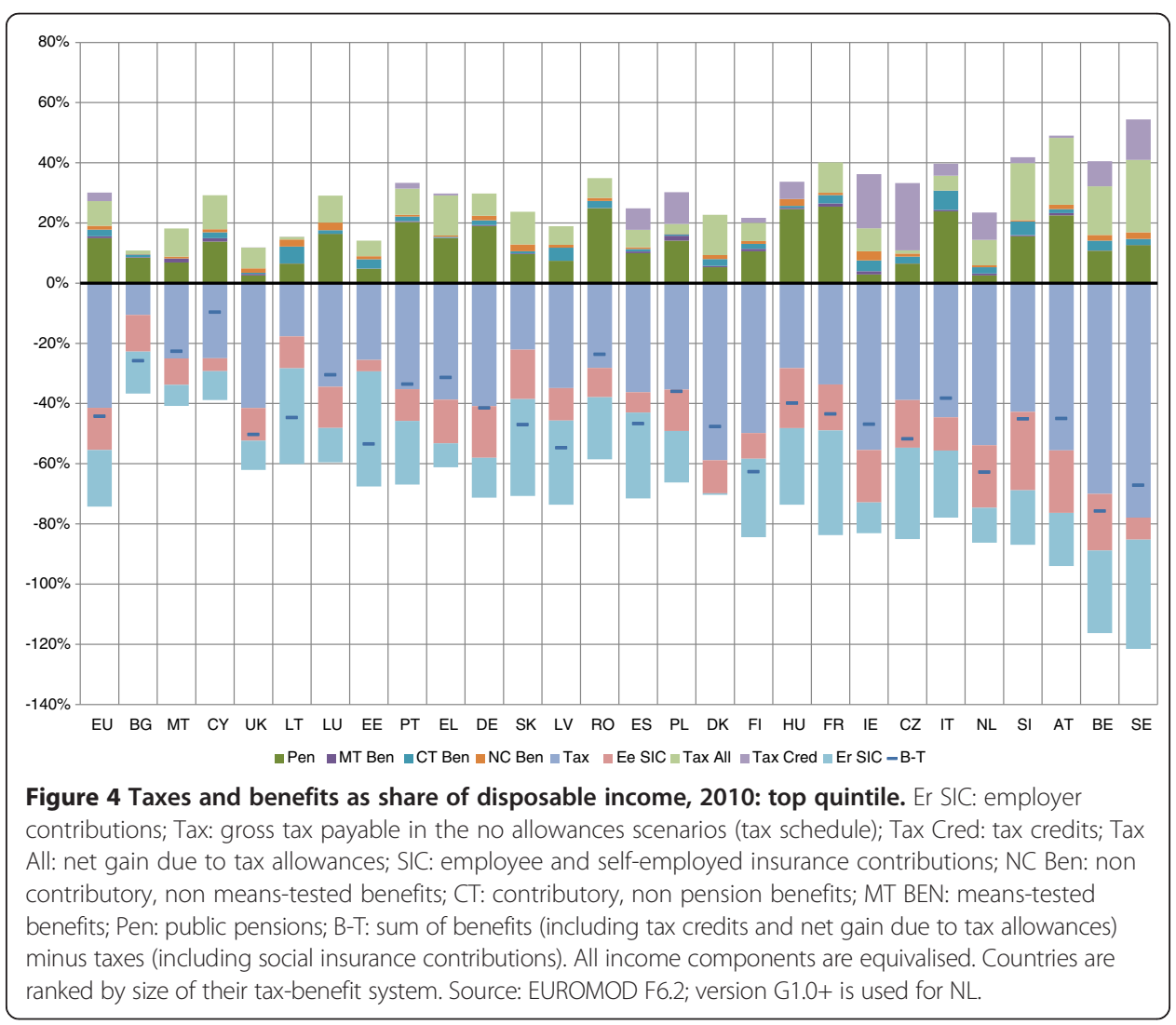


$17 \%$ of disposable income in the bottom quintile but reaches $-55 \%$ at the top. Large reductions in income from the tax benefit system at the top are mainly due to direct income taxation suggesting that if richer households are to be made to contribute more to the system this will mostly be done via higher taxation.

\subsection{Redistributive effect of taxes and benefits}

We examine the redistributive effect of taxes and benefits by looking at a common and simple measure of inequality, namely the Gini coefficient. We first present measures of how income inequality changes when we exclude a given tax-benefit instrument from the construction of household disposable income. Our measures are based on the generalized Gini index measure (S-Gini), using three different sensitivity levels, i.e. 1.5, 2 and 3. We calculate confidence intervals for all our estimates using bootstrapping.

An overall view of inequality of disposable income levels in the 27 countries as well as in the EU as a whole is given in Figure 5. Three S-Gini series are shown each using a different sensitivity parameter, namely 1.5 (Gini 1), 2 (Gini2) and 3 (Gini 3). Higher values of the sensitivity parameters indicate the corresponding S-Gini measure places more weight on individuals at the bottom of the distribution. Countries are ranked by the size of their tax-benefit system. Although the last seven countries do have lower levels of inequality, there is not necessarily a straightforward relationship between the size of the tax-benefit system and inequality of disposable income. Not surprisingly, inequality is much higher when considering the EU as whole. This measure incorporates not only within country inequality but also income inequality between countries.

The next 9 graphs show changes in the three S-Gini indicators if one income component of disposable income would be excluded and inequality re-calculated based on remaining

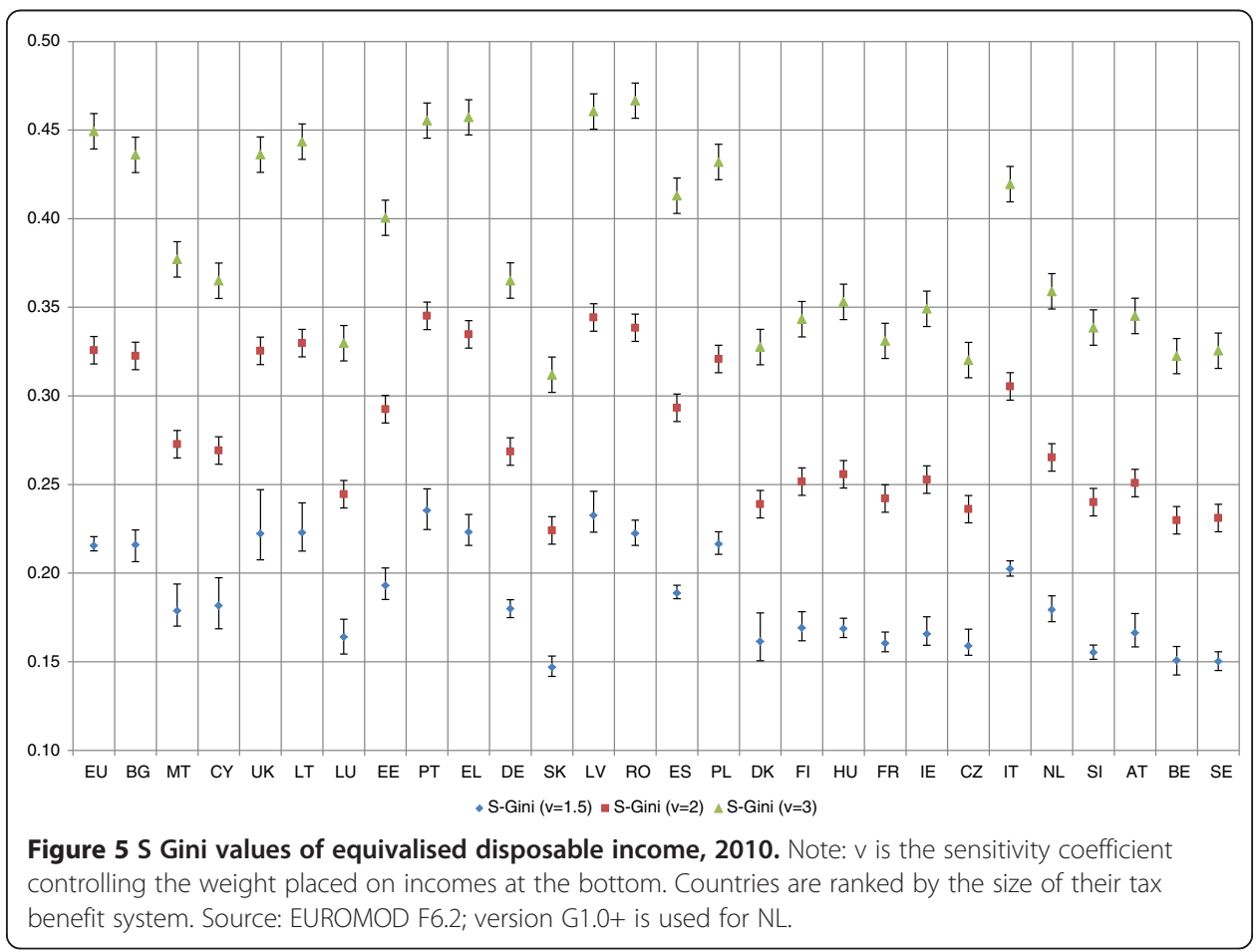


income. This difference is a measure of the redistributive effect of the respective income component. A positive number indicates that excluding the respective income component makes the resultant income distribution more unequal, i.e. the income component redistributes from the top to the bottom of the distribution.

First, we show in Figure 6 the redistributive effect of the entire tax-benefit system. In effect, this involves comparing disposable incomes with market incomes. In all 27 countries, the tax benefit system generates some degree of redistribution. However, the magnitude of the redistributive effect varies substantially across countries. For example, in the case of $\mathrm{v}=2$, the reduction in the S-Gini index after applying tax-benefit rules on market incomes ranges from 11 points in Cyprus to 26.5 points in Belgium and 25.3 points in Hungary. In addition to Belgium and Hungary, other countries where the redistributive effect of the tax-benefit system is high are France, Ireland, Germany, the Czech Republic and Luxembourg. Generally speaking, redistribution measures based on the three S-Gini indexes generate broadly consistent country rankings. In some cases though, reversals occur. For example, the Hungarian tax-benefit system appears to be more redistributive than the French one when using $v=1.5$ and $v=2$ but not when using $\mathrm{v}=3$. This occurs because the three indexes place different weights on the various parts of the income distribution. In this case, the French system being particularly redistributive when using $v=3$ suggests that French taxes and benefits are particularly effective in shifting income towards the bottom of the distribution. All three indexes show a mild positive association with the size of the tax benefit system.

When examining the $\mathrm{EU}$ as a whole, the redistributive effect of taxes and benefits is around 20 points, which is well above the country average. In fact, the achieved redistributive effect can be considered relatively large given that tax-benefit systems are

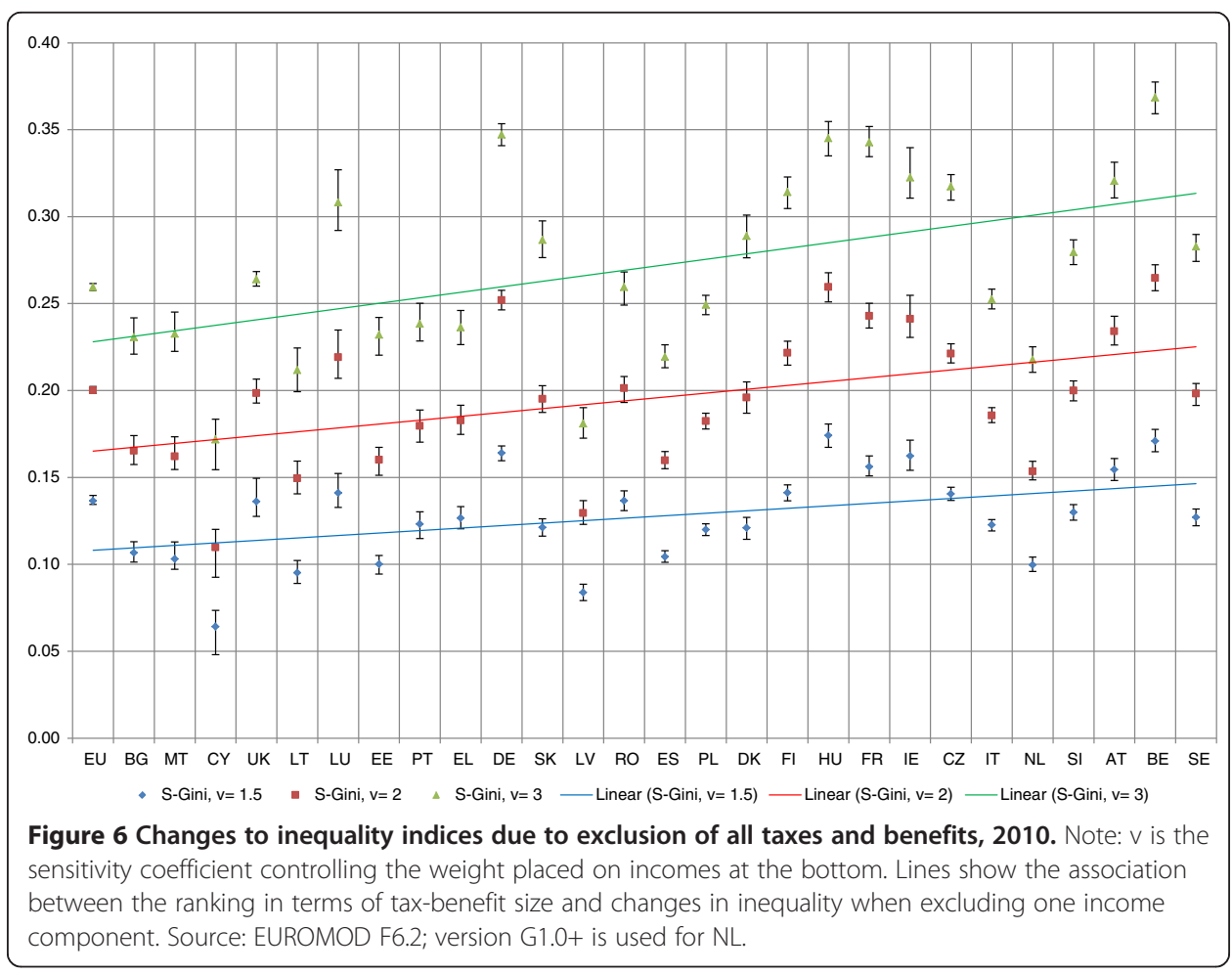


national -and thus able to redistribute only within countries-whereas some portion of EU inequality may be found between countries ${ }^{14}$.

Figure 7 shows the changes in the three S-Gini indicators if pension income would be excluded from disposable income. Public pensions clearly redistribute towards the bottom in all countries. Ireland and the UK where public pensions are a less important source of income in old-age are outliers, but even in their case the redistributive nature of pensions is unambiguous. Interestingly, pension income is more redistributive in countries with larger tax benefit systems. The relationship is most striking when more emphasis is put on the poor when computing the level of inequality (S-Gini with $v=3$ ).

Changes in the S-Gini indexes when excluding means-tested benefits are presented in Figure 8. As expected, inequality measures increase across the board when meanstested benefits are excluded from disposable income. The three inequality measures are most affected in countries where means-tested benefits are relatively important such as the UK, Ireland, France and the Netherlands. There is however no association with the size of the tax benefit system as a whole. The lack of a relationship between the redistributive capacity of means-tested benefits and size of the overall tax- benefit system is partly attributable to the fact that sizeable means-tested components (and thus a larger inequality reducing effect) may be found both in countries with smaller tax-benefit systems (UK, Ireland) as well as in countries with more extensive systems (France, Netherlands).

We repeat the exercise and exclude contributory benefits. Results are displayed in Figure 9. Disregarding contributory benefits leads to small increases in the S-Gini indexes in most countries. This suggests that contributory benefits are unlikely to significantly alter the income distributions and thus their potential for vertical redistribution

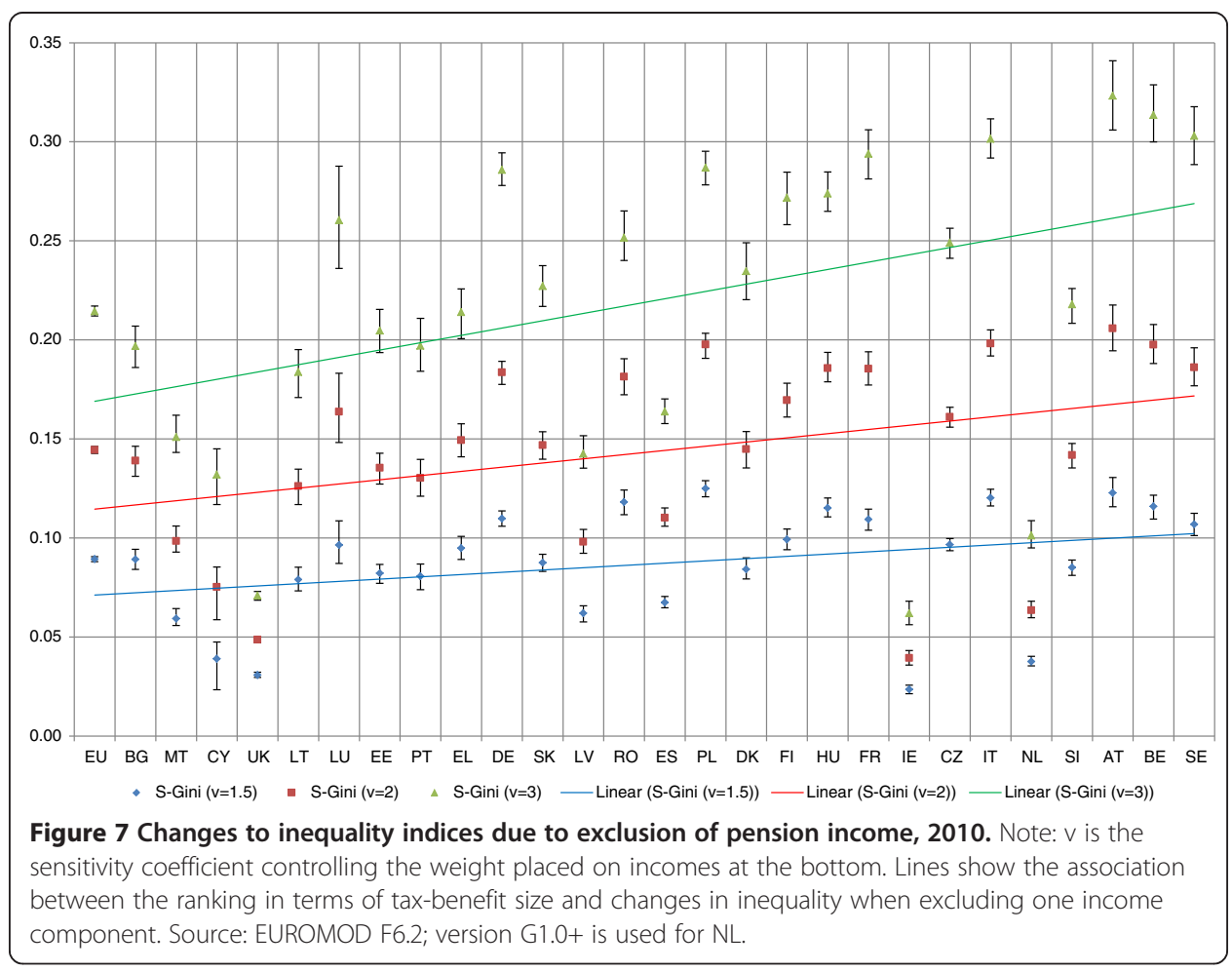




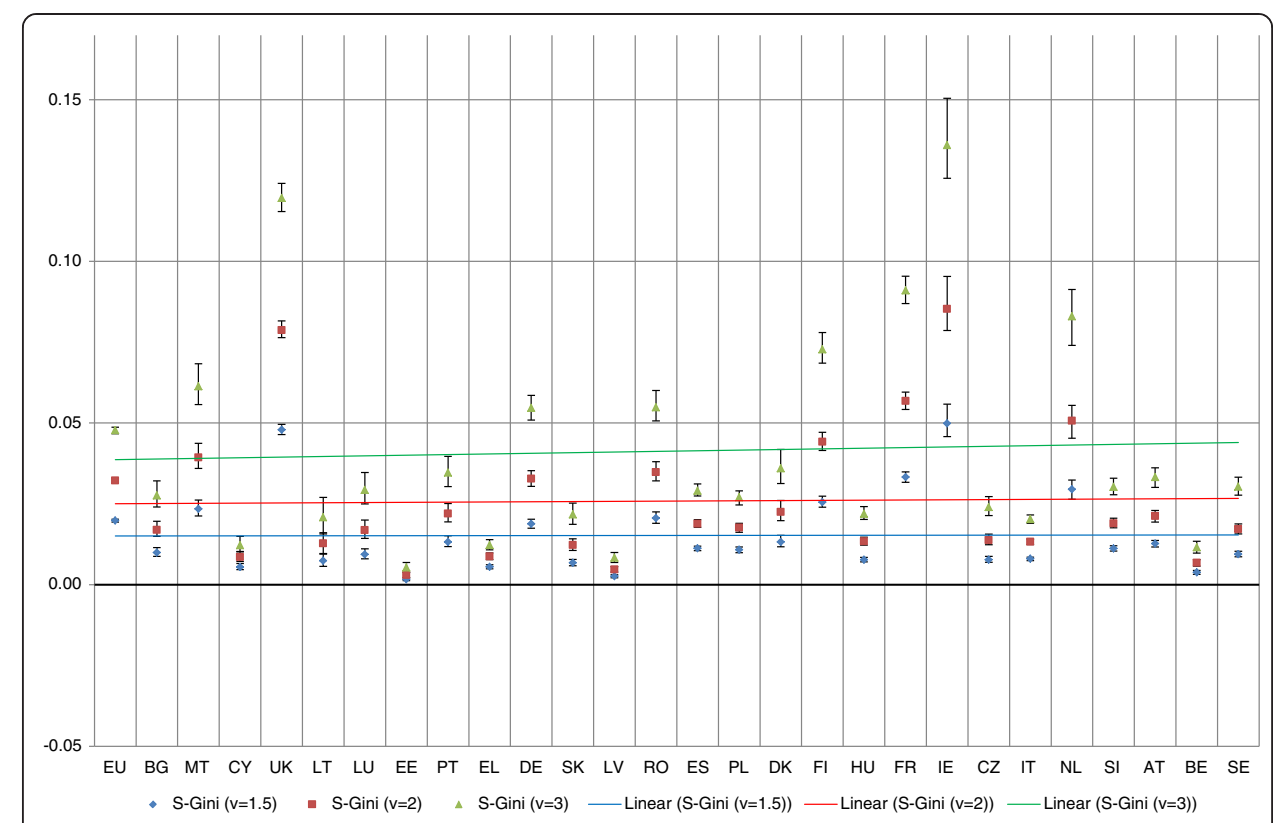

Figure 8 Changes to inequality indices due to exclusion of means-tested benefits, 2010. Note: $v$ is the sensitivity coefficient controlling the weight placed on incomes at the bottom. Lines show the association between the ranking in terms of tax-benefit size and changes in inequality when excluding one income component. Source: EUROMOD F6.2; version G1.0+ is used for NL.

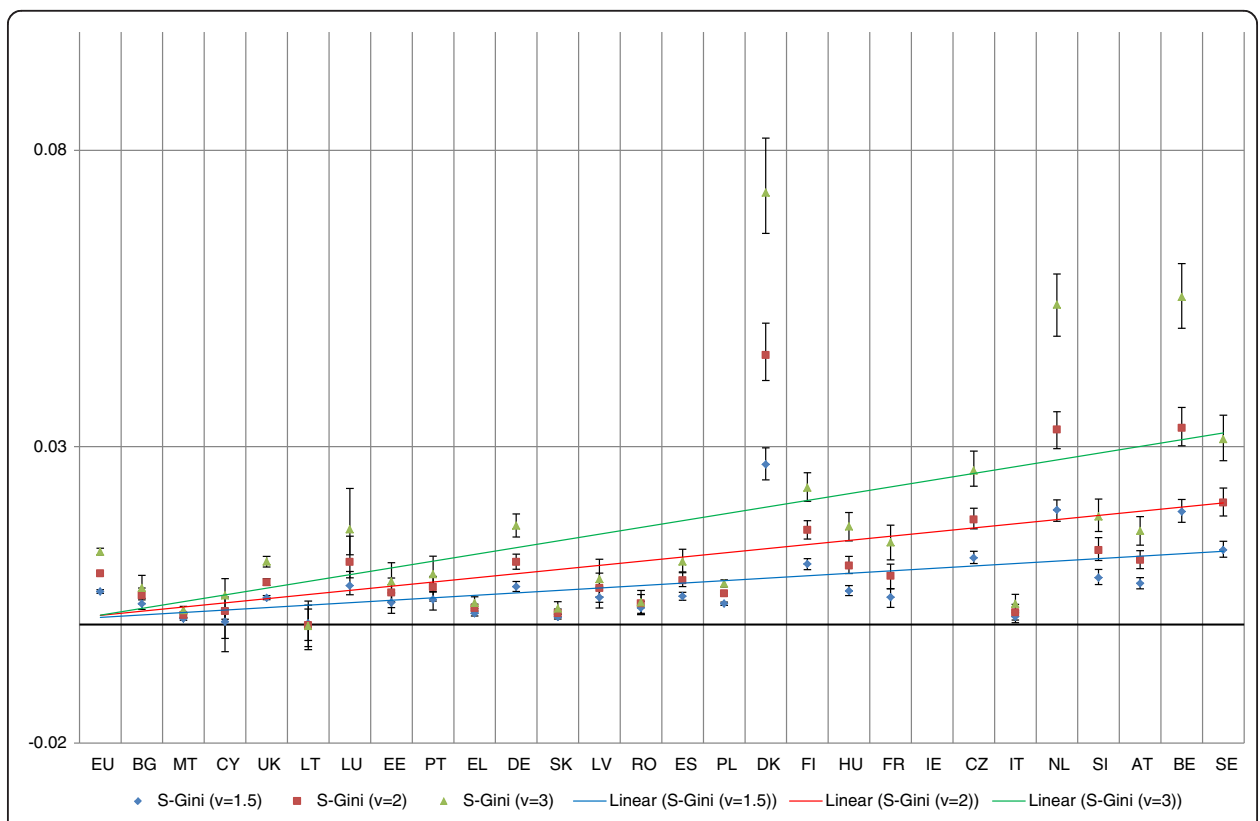

Figure 9 Changes to inequality indices due to exclusion of contributory benefits, 2010. Note: $v$ is the sensitivity coefficient controlling the weight placed on incomes at the bottom. Lines show the association between the ranking in terms of tax-benefit size and changes in inequality when excluding one income component. Source: EUROMOD F6.2; version G1.0+ is used for NL. 
is limited. Exceptions are Belgium, Denmark, and Netherlands where their impact is more significant. Note that all four countries have relatively larger tax-benefit systems.

Likewise, non contributory non means-tested benefits have a reduced redistributive effect. This can be clearly seen in Figure 10. The one exception is Hungary where all three S-Gini measures go up substantially when excluding non contributory benefits from disposable income. Denmark, Sweden and Luxembourg also have above average redistributive effects of non-contributory benefits. There is little indication that the vertical redistributive effect of non contributory benefits varies with the size of the tax benefit system.

In addition to pensions, taxes are the instrument most likely to affect the distribution of disposable income. Like pensions, they are generally progressive albeit their redistributive effect is relatively muted in the New Member States as well as South European countries. The redistributive effect of gross taxes is relatively high whenever the size of the tax-benefit system is large. The converse is however not true. For example, taxes are strongly redistributive in the UK (small size of the tax-benefit system) as well as Ireland and Germany (medium size of the tax-benefit system). As expected, the redistributive effect of the schedule is low in countries with flat rate taxes such as Bulgaria, Estonia or Romania (Figure 11). While income tax is flat rate in the Slovak Republic as well, the higher redistributive effect of the tax schedule stems from the fact that pensions and benefits which tend to be more important to lower income groups are not taxable. Likewise, the tax schedule has a notable redistributive effect in the Czech Republic despite the existence of a flat-rate regime, due to the inclusion of employer contributions into the tax base. The most extensive redistribution via the tax schedule

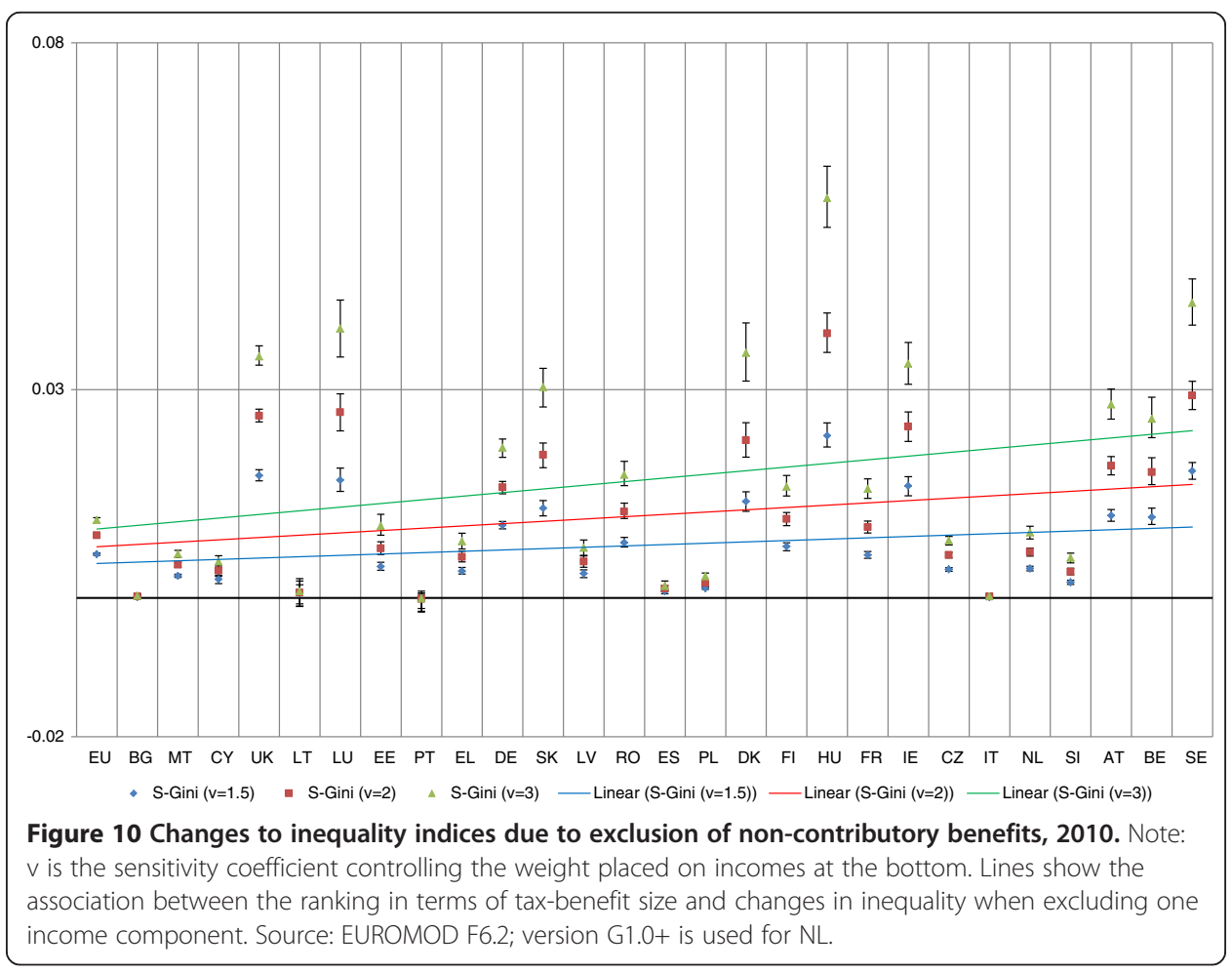




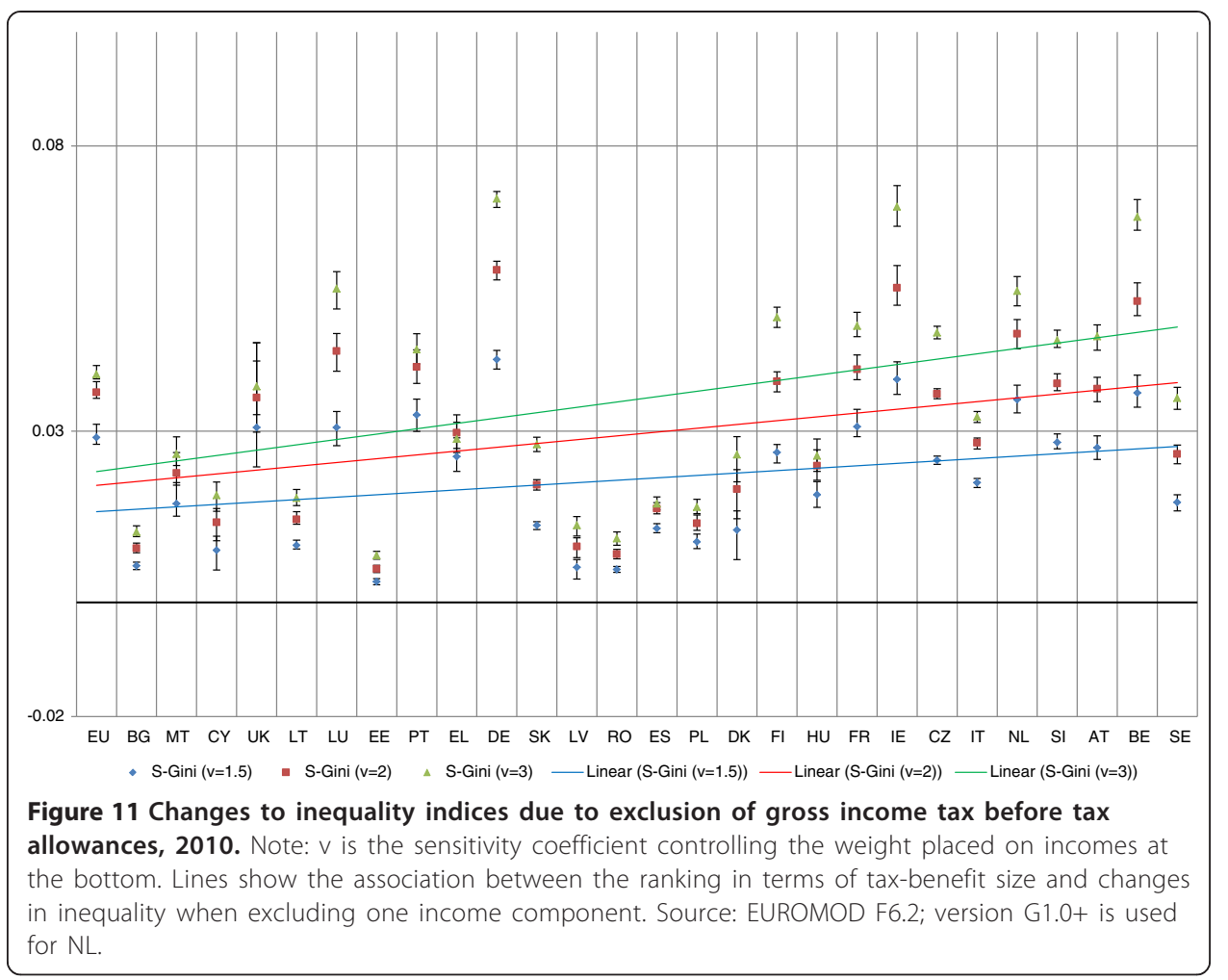

is found in Germany, possibly due to the combination of a progressive tax schedule with the so-called 'progressivity adjustment' ${ }^{15}$.

Neither tax allowances nor tax credits are particularly relevant for vertical redistribution (Figures 12 and 13). In fact, tax allowances are generally slightly regressive, as the negative values of the change in the S-Gini indexes indicate. France, Belgium, and Ireland are the countries where tax allowances do most to increase inequality. The close interlinking of tax allowances with the tax schedule is clearly visible. Tax allowances tend to be redistributive in a framework of flat-rate taxation (for example, Romania or Estonia). On the contrary, they tend to be regressive in a context of progressive taxation.

Tax credits on the other hand are slightly progressive with the exception of Sweden and the Czech Republic where their effect is to mildly increase inequality ${ }^{16}$. Yet, the redistribution they effect is virtually negligible. S-Gini coefficients computed when they are excluded from disposable income are very similar to baseline coefficients.

Lastly, social insurance contributions generally do contribute to redistribution albeit much less than pensions or the tax schedule (Figure 14). Although the changes in the S-Gini indexes when they are excluded are generally positive, substantively they are relatively small. Ireland and Belgium are the countries where social insurance contributions do most to vertically redistribute. There are also countries where their effect is to increase inequality, such as Romania or the Netherlands, possibly due to (low) caps on contributions. No relationship between the redistributive effect of social contributions and the size of the tax benefit system becomes apparent. 


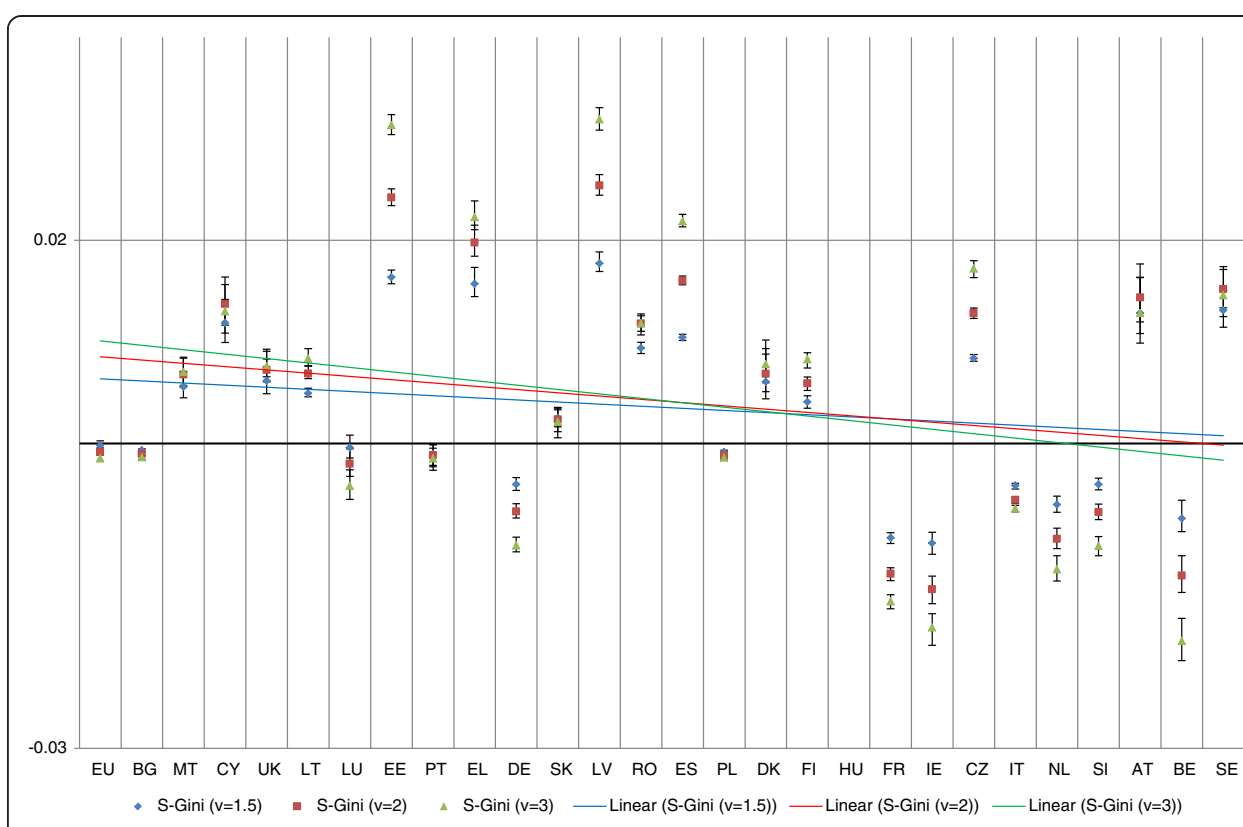

Figure 12 Changes to inequality indices due to exclusion of net gain attributable to tax allowances, 2010. Note: $v$ is the sensitivity coefficient controlling the weight placed on incomes at the bottom. Lines show the association between the ranking in terms of tax-benefit size and changes in inequality when excluding one income component. Source: EUROMOD F6.2; version G1.0+ is used for NL.

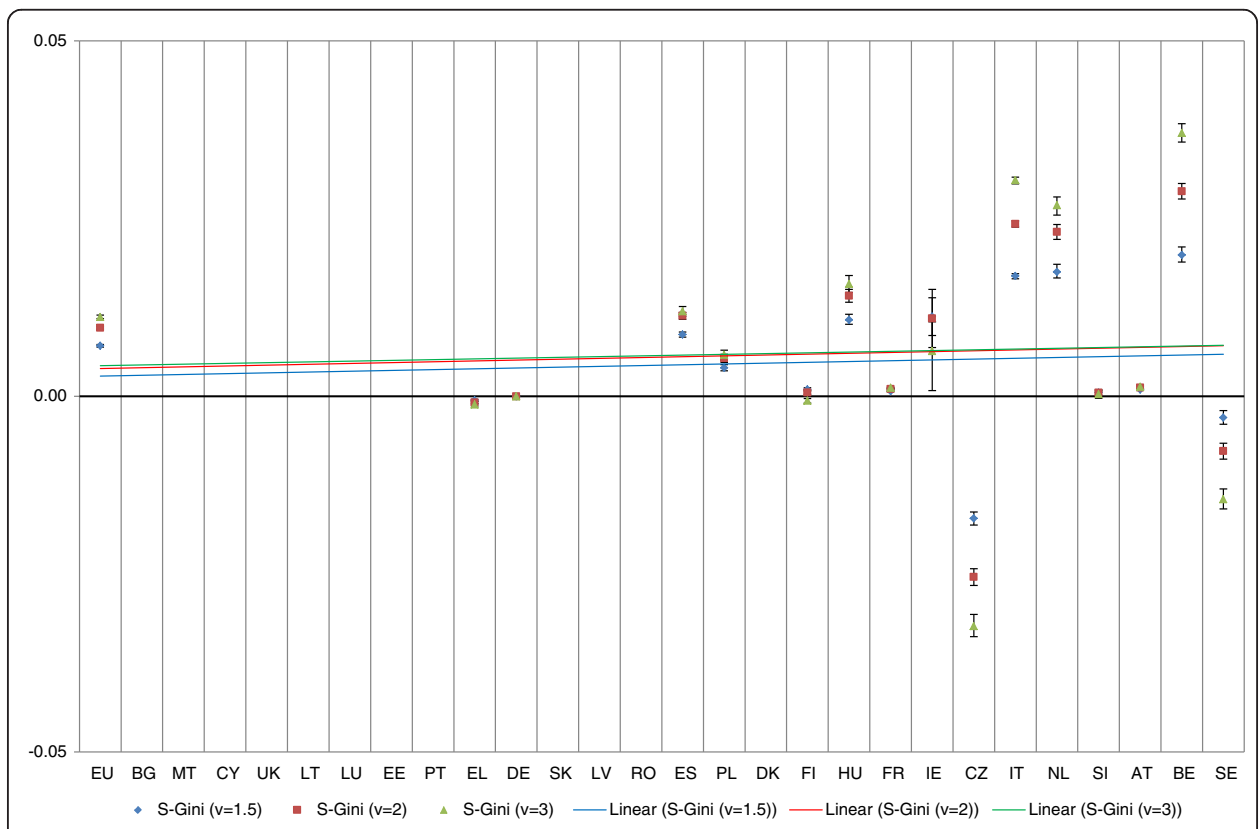

Figure 13 Changes to inequality indices due to exclusion of tax credits, 2010. Note: $v$ is the sensitivity coefficient controlling the weight placed on incomes at the bottom. Lines show the association between the ranking in terms of tax-benefit size and changes in inequality when excluding one income component. Source: EUROMOD F6.2; version G1.0+ is used for NL. 


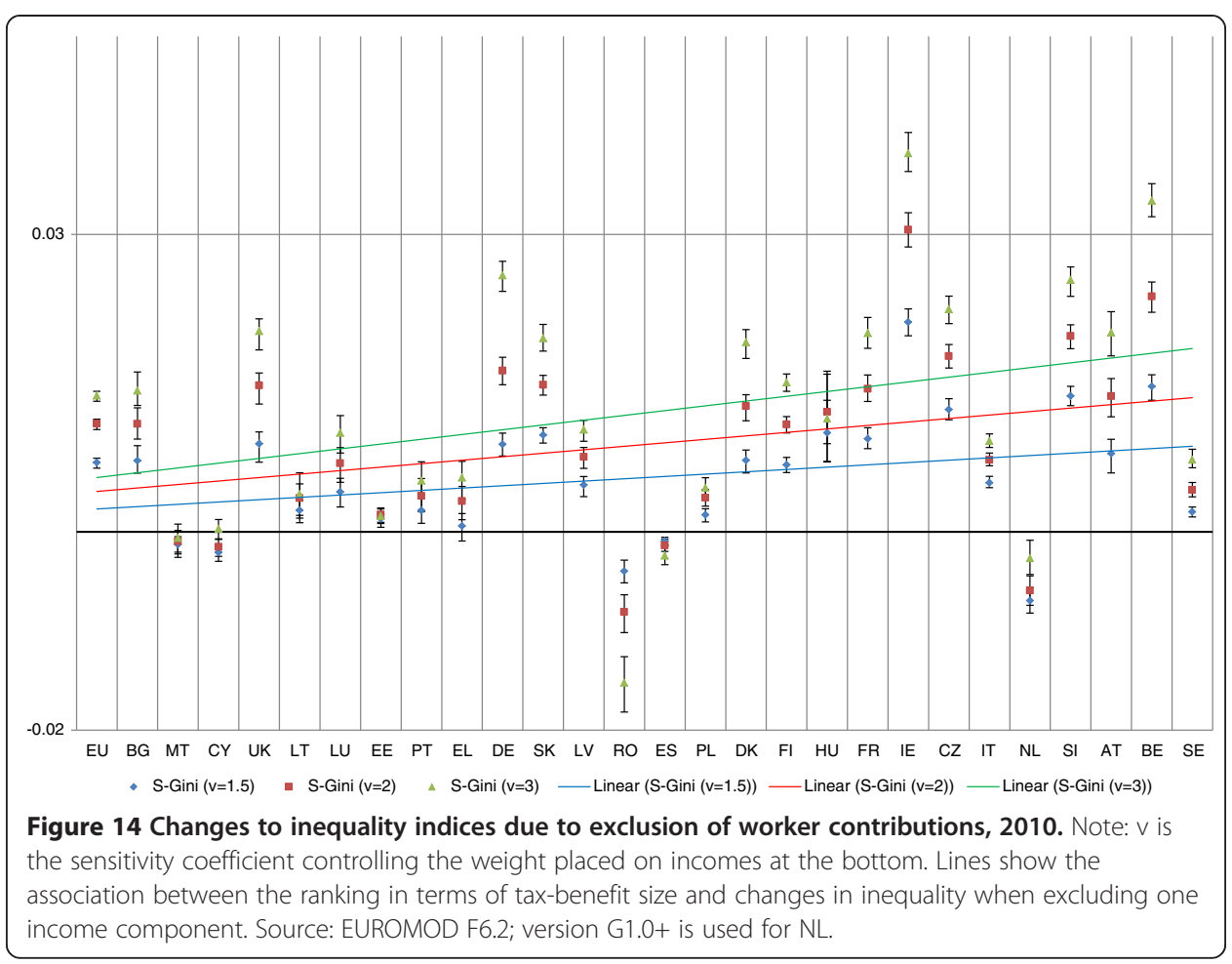

\subsection{Marginal effects}

Next, we look at the drivers of disposable income inequality from a different perspective. To this end, we use a standard Gini $(v=2)$ decomposition to show the contribution of each type of income component to overall inequality. The contribution depends on the size of the income component (i.e. its share of disposable income), how unequally it is distributed and its correlation with final household disposable income. The effect of a marginal increase in a given income source on the Gini coefficient of disposable income offers an intuitive way of summarizing the contribution to overall inequality of each income component. The percent change in the Gini index of household disposable income associated with a 1 percent marginal increase in a given tax benefit income instrument is shown for the 27 countries and for the EU as a whole in Figure 15 below.

Clearly in all countries the largest factor contributing to inequality is market incomes. This confirms the results of the previous section that on the whole, tax-benefit systems redistribute significantly. Overall, the strongest effect on disposable income inequality is exerted by pensions and taxes (i.e. tax schedules). Both tend to be redistributive. The prominence of pensions and taxes is not surprising given that they are the largest taxbenefit instruments affecting disposable income (see Figure 1).

In the large majority of EU countries, public pensions are the most important income source in old-age. Since many pension systems do incorporate important redistributive elements such as minimum pensions or caps on benefits, public pensions tend to reduce inequality. Pensions have the strongest negative effect on the Gini coefficient in Belgium and the Czech Republic. Their effect is much lower in countries where private pensions are an important part of the income of the elderly such as UK or Ireland but also in countries where their distribution is closely aligned with that of market income such as Romania, Portugal, Austria, Hungary, or Italy. Luxembourg and France are the 


\begin{tabular}{|c|c|c|c|c|c|c|}
\hline EU & bg & $\mathrm{mt}$ & cy & It & uk & lu \\
\hline Ee SIC & Ee SIC $\quad 1$ & Ee SIC & Ee SIC & Ee SIC & Ee SIC & Ee SIC $\quad 1$ \\
\hline Tax All $\frac{1}{!=}$ & Tax All & Tax All & Tax All ! & Tax All & Tax All & Tax All \\
\hline NC Ben 1 & NC Ben & NC Ben & NC Ben & NC Ben & NC Ben- & NC Ben \\
\hline CT Ben ? & СT Ben & CT Ben & СT Ben & CT Ben & Ст Ben & СT Ben \\
\hline Mkt Inc & Mkt Inc $\rightleftharpoons$ & Mkt Inc & Mkt Inc & Mkt Inc & Mkt Inc & Mkt Inc \\
\hline-0.50 & $\begin{array}{ll}-0.50 & 0.50\end{array}$ & $\begin{array}{ll}-0.50 & 0.50\end{array}$ & $\begin{array}{ll}-0.50 & 0.50\end{array}$ & $-0.50 \quad 0.50$ & $\begin{array}{ll}-0.50 & 0.50\end{array}$ & $\begin{array}{ll}-0.50 & 0.50\end{array}$ \\
\hline & pt & & de & sk & Iv & ro \\
\hline Ee SIC $\square 1$ & Ee SIC & $\mathrm{Ee} \mathrm{SIC}$ & Ee SIC $\quad 1$ & Ee SIC & Ee SIC & $\mathrm{Ee} \mathrm{SIC} \square$ \\
\hline Tax All & Tax All & Tax All ! & Tax All $\stackrel{1}{=}$ & Tax All & Tax All & Tax All \\
\hline NC Ben $\quad i$ & NC Ben & NC Ben & NC Ben & NC Ben & NC Ben & NC Ben \\
\hline CT Ben & CT Ben & СТ Ben & СТ Ben & Ст Ben & Ст Ben- & СТ Ben \\
\hline Mkt Inc & Mkt Inc & Mkt Inc & Mkt Inc $\Longrightarrow$ & Mkt Inc & Mkt Inc $\Longrightarrow$ & Mkt Inc $\stackrel{-H}{\longrightarrow}$ \\
\hline $\begin{array}{ll}-0.50 & 0.50\end{array}$ & $\begin{array}{ll}-0.50 & 0.50\end{array}$ & $\begin{array}{ll}-0.50 & 0.50\end{array}$ & -0.50 & -0.50 & $\begin{array}{ll}-0.50 & 0.50\end{array}$ & $\begin{array}{ll}-0.50 & 0.50\end{array}$ \\
\hline es & pl & $\mathbf{d k}$ & fi & hu & fr & Te \\
\hline Ee SIC $\square !$ & $\mathrm{EeSIC}$ & Ee SIC & Ee SIC & Ee SIC & Ee SIC $\quad$ I & Ee SIC \\
\hline Tax All & Tax All & Tax All & Tax All & Tax All] & Tax All & Tax All i \\
\hline NC Ben & NC Ben & NC Ben & NC Ben & NC Ben & NC Ben & NC Ben \\
\hline СT Ben & Ст Ben & CT Ben & Ст Ben & СT Ben & Ст Ben & CT Ben \\
\hline Mkt Inc $\square$ & Mkt Inc & Mkt Inc & Mkt Inc & Mkt Inc- & Mkt Inc & Mkt Inc- \\
\hline $\begin{array}{ll}-0.50 & 0.50 \\
\end{array}$ & $\begin{array}{ll}-0.50 & 0.50 \\
\end{array}$ & $\begin{array}{ll}-0.50 & 0.50\end{array}$ & -0.50 & -0.50 & -0.50 & $\begin{array}{ll}-0.50 & 0.50\end{array}$ \\
\hline cz & & & si & at & be & se \\
\hline Ee SIC & Ee SIC & $\mathrm{EeSIC}$ & Ee SIC & Ee SIC & Ee SIC & Ee SIC \\
\hline Tax All & Tax All & Tax All & Tax All & Tax All & Tax All & Tax All \\
\hline NC Ben 1 & NC Ben & NC Ben I & NC Ben $\quad I$ & NC Ben & NC Ben ! & NC Ben \\
\hline CT Ben i & CT Ben & СT Ben ; & CT Ben $\quad$ i & CT Ben & CT Ben & СТ Ben ! \\
\hline Mkt Inc & Mkt Inc & Mkt Inc $\square$ & Mkt Inc & Mkt Inc $\stackrel{4}{\longrightarrow}$ & Mkt Inc & Mkt Inc \\
\hline $\begin{array}{ll}-0.50 & 0.50\end{array}$ & -0.50 & -0.50 & -0.50 & 0.50 & $\begin{array}{ll}-0.50 & 0.50\end{array}$ & -0.50 \\
\hline
\end{tabular}

Figure 15 Redistributive* effects of marginal increases in tax benefit income components, 2010. *Percent change in the Gini coefficient of disposable income after a 1 percent increase in the respective income components. Er SIC: employer contributions; Tax: gross tax payable in the no allowances scenarios (tax schedule); Tax Cred: tax credits; Tax All: net gain due to tax allowances; SIC: employee and self-employed insurance contributions; NC Ben: non contributory, non means-tested benefits; CT: contributory, non pension benefits; MT BEN: means-tested benefits; Pen: public pensions; Source: EUROMOD F6.2; version G1.0+ is used for NL. 
only countries where increasing pensions would increase inequality, albeit the magnitude of the increase would be very small.

The other main element of the tax-benefit system affecting inequality is gross taxation before allowances (tax schedules). The effect of this is redistributive in all countries. Nonetheless, the scale of the redistribution varies. The strongest effects are found in Luxembourg, Ireland, Germany, Netherlands, and Belgium. All are countries using progressive taxation regimes. On the contrary, in countries with flat rate taxation such as Bulgaria, Estonia or Romania, an increase in the gross tax has a minimal impact on inequality. The clear exceptions to this pattern are the Czech and the Slovak Republics, possibly due to the way they define taxable income (see section 3.3 above).

Not all countries use tax credits in their fiscal regime but where they do, tax credits tend to have a mild redistributive effect. Italy and the Netherlands are the only countries where increasing income from tax credits would lower inequality substantially. Sweden is something of an exception as its negative capital tax credit tends to be regressive. Similarly tax credits in the Czech Republic increase inequality, possibly due to the fact that their maximum amounts are very high meaning only earners in the top of the income distribution are able to take advantage of the entire credit.

The effect of tax allowances on inequality as measures by the Gini coefficient is small. The direction of their impact on inequality varies from country to country. Thus, increasing tax allowance income by one percent would lower inequality in Estonia, Latvia, Czech Republic, Spain and Greece by between a 14th and a 20th of a percentage point. It would increase it in France, Belgium and Ireland by approximately a $20^{\text {th }}$ of a percentage point. Note that albeit statistically significant, these effects are small in magnitude.

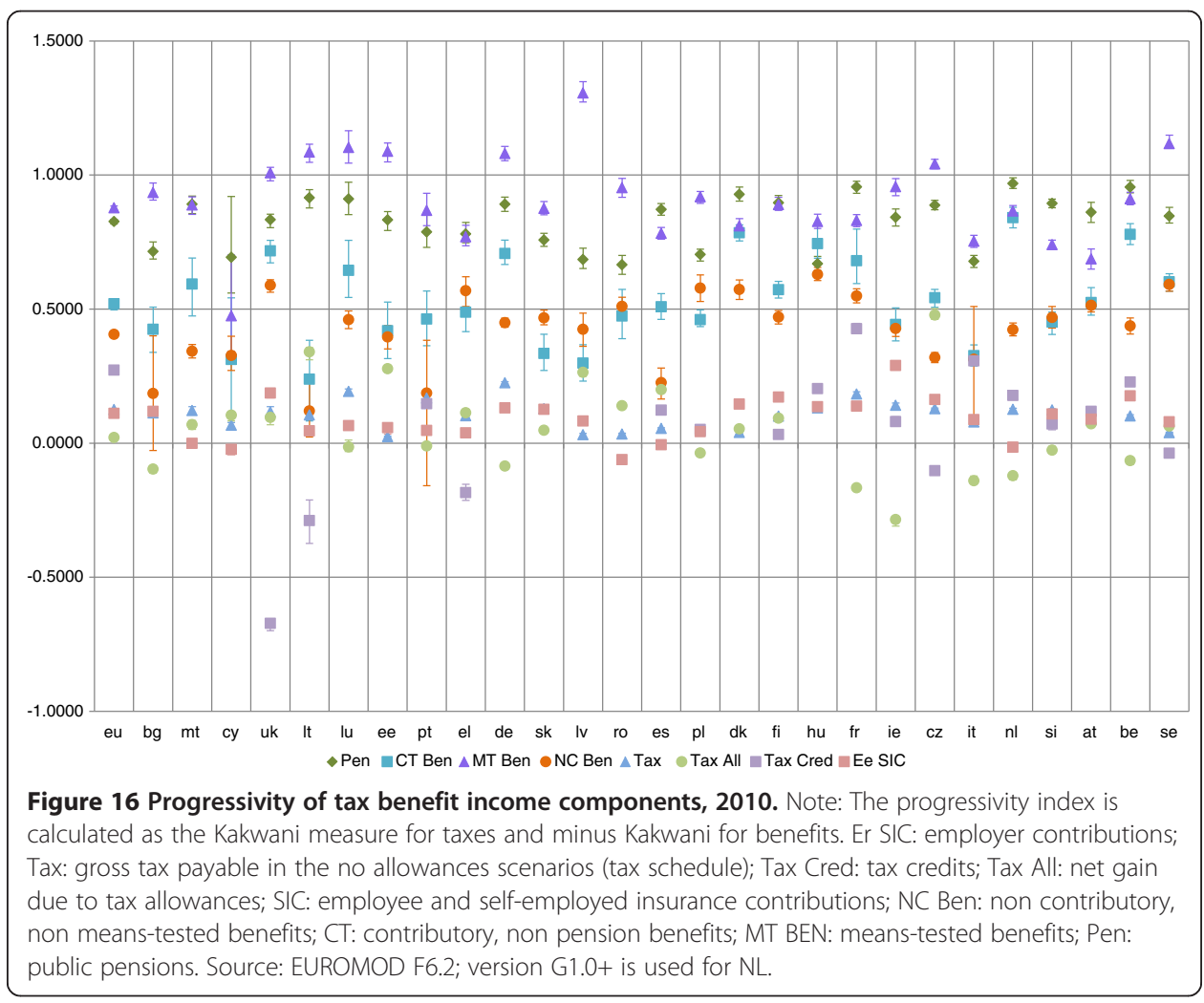


The other type of taxation that we consider in this exercise, namely worker insurance contributions, is much less redistributive. Their strongest equalizing impact is found in Ireland, Slovenia, the Czech Republic and Belgium. However, social insurance contributions are not always redistributive. In some cases, such as for example in Romania or the Netherlands, increasing contributions would actually increase inequality. This is most likely due to caps on contributions.

By design, means-tested benefits are negatively correlated with disposable income. As such, their effect is always to decrease inequality of market incomes. In most countries, their effect is relatively muted due to their small size. However, there are a few countries where their impact is notably larger. Ireland and UK stand out in particular but the pattern is visible in France and to a lesser extent in Finland and the Netherlands.

Non contributory, non means-tested benefits are generally redistributive but their contribution is small. They reduce inequality most in Luxembourg and Hungary and have an above average impact on inequality in the UK, Slovakia, Denmark, Ireland, Sweden and Austria. Finally, contributory benefits have the least potential to affect inequality. Their effect at the margin is closest to zero (Denmark, Sweden, Belgium and the Netherlands are exceptions). This is perhaps not surprising given they generally replace market incomes in special contingencies.

\subsection{How progressive are taxes and benefits?}

The redistributive effect of an income component largely depends on two factors, namely its size and its progressivity (see equation 3a). This section examines the progressivity -as measured by the Kakwani index-of the eight income components that together make up the tax benefit system ${ }^{17}$. Figure 16 plots the calculated progressivity indexes for 27 countries of the EU (the index is calculated as the Kakwani index in the case of taxes and minus the Kakwani index in the case of benefits; thus, positive numbers always indicate more progressivity).

The large majority of the components of the tax-benefit system are progressive. In fact, there are only three types of tax-benefit instruments that are regressive in some countries. These are tax allowances, tax credits and employee social insurance contributions. On the other hand, means-tested benefits and but also pensions are the instruments that appear to be most progressive. The strong progressivity of means-tested benefits is not surprising given their inverse relationship to income. In the case of pensions, the strong progressivity is to some extent a mechanical effect. In the absence of pensions-many pensioners would have no or little income. As such, public pensions are negatively correlated to "non-pension" income.

The largest cross-national variation in the values of the progressivity index is found in the case of contributory and non-contributory non-means-tested benefits. For example, in the case of contributory benefits, progressivity ranges from 0.84 in Netherlands and 0.78 in Denmark to 0.23 In Lithuania and 0.29 in Latvia. This suggests that despite being generally related to previous earnings, the impact of contributory benefits on the income distribution may vary a lot depending on their actual design as well as the features of the wider tax-benefit system they are embedded in. Similarly, non-contributory benefits range in progressivity from 0.63 in Hungary and 0.59 in Sweden to 0.11 in Lithuania and 0.18 in Portugal and Bulgaria. Given that by design they are not related to market incomes, we would expect this category of tax-benefits instruments to be generally progressive. However, non-contributory benefits are usually 
categorical benefits. Depending on the ranking in the income distribution of the groups they target, non-contributory benefits may have a larger or smaller effect on inequality.

Another somewhat surprising result is the moderate progressivity of the tax schedule. Remember that the tax schedule captures the progressivity of the gross tax payable in the absence of allowances. In a large number of countries, such as for example Latvia, Lithuania or France, the progressivity of either tax allowances or tax credits or both is positive suggesting that final net taxes are more progressive than what is suggested by the tax schedule alone. Unsurprisingly, the most progressive schedules are the ones with many tax brackets such as those in Germany, Luxembourg or France.

Finally, at the EU level both benefits and taxes are progressive, albeit benefits are clearly much more progressive than taxes. The ranking of tax-benefit instruments on the progressivity index is very similar to the general pattern found across EU countries, i.e. pensions and means-tested benefits are the most progressive elements whereas tax allowances and employee social insurance contributions are the least. Finally, at the EU level-contributory benefits appear to be more progressive than non-contributory ones.

\section{Conclusions}

In this paper, we analyze the redistributive effects of taxes and benefits in the 27 countries that form the European Union. We rely on various Gini class measures to assess the redistributive effect, as well as the contribution to overall inequality of eight different tax-benefit instruments, i.e. public pensions, means-tested benefits, contributory benefits, non-contributory non means-tested benefits, direct taxes, tax allowances, tax credits and worker insurance contributions. In line with previous research, we find that, overall, tax benefit systems do succeed in redistributing significant portions of market income and in doing so they reduce inequality considerably. However, the extent of the redistribution varies markedly across countries. Although precise country rankings vary somewhat depending on the Gini measure used, all indicators suggest that Belgium, Hungary, Ireland, France, Germany and the Czech Republic reduce inequality significantly via their taxes and benefits. In contrast, tax-benefit systems reduce inequality least in Cyprus, Malta, Bulgaria, Latvia and Lithuania. According to the widest used Gini measure $(v=2.0)$, inequality reduction is more than twice as large in the former group of countries compared to the latter.

The main instruments through which most of the tax-benefit systems considered in our analysis effect their equalizing action are public pensions and direct taxes. The strong redistributive effects of public pensions and the income tax schedule are mainly attributable to their sizeable share in final disposable income. Both pensions and taxes redistribute more in countries where the tax-benefit system is more extensive (as measured by the relative size of taxes and benefits as a percentage of disposable income), reinforcing the idea that the size of the tax-benefit income components is the strongest determinant of their redistributive effect.

By and large, countries with higher levels of redistribution also are the countries where direct taxation is higher. However, there is no one to one relationship between the taxation level and the extent of redistribution effected via the tax-benefit system. In particular, some countries with medium levels of direct taxation such as France and Germany are still able to generate high levels of redistribution. In addition, an increased taxation level does not necessarily equate with more extensive redistribution. For 
example, Sweden ranks first according to the level of direct personal taxes but only $14^{\text {th }}$ according to the reduction in the Gini coefficients determined by taxes and benefits. Similarly, Netherlands, Latvia, Spain and Italy have relatively high levels of direct taxation but only moderate or low levels of redistribution. To some extent, these results may be explained by the structure and complexity of the tax system. On the one hand, high gross taxation levels may be compensated by significant tax concessions resulting in much lower net tax burdens (Sweden, Spain, and Netherlands). On the other hand, the redistribution potential of some tax schedules is limited by low progressivity (Sweden, Spain, and Latvia).

The level of taxation also appears to be linked to its complexity. Thus, direct tax regimes in the EU tend to place themselves on a continuum with simple lower level schedules at one end and more complex higher schedules at the other. In effect, more complex elements such as tax credits or tax allowances are drawn upon to reduce final net tax liabilities.

New Member States do not appear to form a distinct cluster either in terms of the tax-benefit size or in terms of redistribution. The only peculiarity that is common to them but also to Southern European countries is that their direct tax policies and tax schedules in particular, tend to be comparatively less redistributive. One possible explanation is the comparatively widespread use of flat-rate taxation in the Eastern European region.

The influence of non-pension contributory and that of non-contributory benefits in disposable income inequality is largely muted. This is mostly due to their relatively small share of disposable income which is a general pattern across the EU. On the other hand, these are also the types of benefits where cross-national variation in progressivity is widest. One possible explanation might be that policy design in these two categories of benefits potentially varies more than in the case of the other tax-benefit instruments.

The disaggregation of direct taxation into schedules, tax credits and a part attributable to tax allowances showed that redistribution is effected mainly via the schedules. The redistributive effect of tax schedules is largely due to their size and to a lesser extent to their progressivity. Neither tax allowances nor tax credits influence inequality levels to any great extent. However, it should be kept in mind that the effect of tax allowances and tax credits is critically linked to the design of tax schedules. In particular, tax allowances and tax credits cannot, by design, have a significant impact in the context of low taxation levels. Tax allowances are progressive in a context of flat rate taxation but regressive in a progressive regime. Both tax allowances and tax credits affect inequality much less than means-tested and even non-contributory benefits. This reinforces the idea that the inequality-reducing capacity of fiscal benefits is limited.

To summarize, our results confirm previous findings related to the substantial redistribution achieved via taxes and benefits, as well as to the large variation existent across EU countries. The largest elements of the tax-benefit system (pensions and direct taxes) are also the ones impacting strongest on redistribution despite occasionally having low progressivity. This result is consistent with previous scholarly work on the 'paradox of redistribution' suggesting that extensive, non-targeted social programs are able to redistribute more due to their increased resources (Korpi and Palme 1998; Nelson 2004). Finally, direct transfers, even when not targeted (contributory and non-contributory non-means-tested benefits) are more likely to reduce inequality 
compared to tax concessions (allowances and credits). Thus, fiscal 'spending' is much less likely to be redistributive compared to traditional 'social' spending.

\section{Endnotes}

${ }^{1}$ More information about our simulations can be found in the Methods section.

${ }^{2}$ For example, EU-SILC mixes means-tested and non-means-tested benefits in several of its income variables (family benefits, unemployment benefits etc.).

${ }^{3}$ It also has to be acknowledged that the use of micro-simulation techniques has its own problems. For example, we are not able to fully account for benefit non take-up. As such, our measures of redistribution should be taken as the intended rather than the actual effect of the tax-benefit system. Benefit non-take is explicitly modelled in a few countries where it is a widespread and important phenomenon. These include Belgium, UK, Estonia and Greece. Tax evasion corrections are modelled in Italy and Bulgaria.

${ }^{4}$ More information about EU-SILC can be found here: http://epp.eurostat.ec.europa.eu/ portal/page/portal/microdata/eu_silc.

${ }^{5}$ EUROMOD Country reports covering 2010 policy systems are available online at: https://www.iser.essex.ac.uk/euromod/resources-for-euromod-users/country-reports.

${ }^{6}$ See Duclos and Araar (2006). Poverty and Equity: Measurement, Policy and Estimation with DAD. New York, Springer.A discussion of alternative interpretations of Gini coefficients is provided by Yitzhaki (1998) "More Than a Dozen Alternative Ways of Spelling Gini." Research on Economic Inequality 8: 13-30.

${ }^{7}$ Despite its simplicity and attractiveness, this approach is not free from problems. In the case of an income component $k$ that is constant for all income units, its concentration coefficient will be zero. Therefore, the contribution of component $k$ (calculated as $r_{k}{ }^{*} C_{k}$ ) would be zero, contrary to the general view that that an addition of a constant to all incomes decreases total inequality (Podder (1993) "The disaggregation of the Gini coefficient by factor components and its application to Australia." Review of Income and Wealth 39(1): 51-61.). Note however that the marginal change in the Gini coefficient of disposable income would be negative. The approach is useful for understanding how different income components (in particular taxes and benefits) are distributed and contribute to total income inequality.

${ }^{8}$ For more on methods to compute standard errors on inequality indices see, among others, Yitzhaki (1991). "Calculating Jackknife Variance Estimators for Parameters of the Gini Method." Journal of Business \& Economic Statistics 9(2): 235-239, Ogwang (2000). "A Convenient Method of Computing the Gini Index and Its Standard Error." Oxford Bulletin of Economics and Statistics 62(1): 123-129. and Efron and Tibshirani (1993). An Introduction to the Bootstrap. Boca Raton, FL, Chapman \& Hall, Giles (2004). "Calculating a Standard Error for the Gini Coefficient: Some Further Results." Oxford Bulletin of Economics and Statistics 66(3): 425-433.

${ }^{9}$ Employer contributions, also simulated by EUROMOD, are included in this calculation because the employee-employer share of total contributions varies widely across countries.

${ }^{10}$ Net taxes are simply the sum of gross taxes, tax allowances and tax credits.

${ }^{11}$ The country-level correlation between the size of the tax schedule component (i.e. gross tax payable in the no tax allowance scenario) and the sum of tax credits and gains 
via tax allowances is 0.9 in the sample of 27 countries. To some extent the high correlation is partly mechanical; high tax allowances / tax credits can only be taken advantage of if taxation (i.e. tax schedules) is high enough,

${ }^{12}$ Part of this effect is obviously mechanical; high net taxes can only come about as a result of high tax schedules.

${ }^{13}$ The country level correlation is -0.78 .

${ }^{14}$ This result holds only using PPP adjusted incomes; if Euro amounts are used directly, a much larger share of inequality is found between rather than within countries and thus the impact of taxes and benefits is much smaller.

${ }^{15}$ The adjustment entails the calculation of the applicable tax band including some types of incomes, such as certain benefits, that are not themselves taxable.

${ }^{16}$ The regressive effect of tax credits in Sweden is mostly likely due to the existence of a tax credit for interests paid on mortgages (negative capital income).

${ }^{17}$ Examining the progressivity of the tax-benefit system as a whole does not make sense as benefits and taxes cancel each other out, generating inconsistent results.

\section{Competing interests}

The IZA Journal of European Labor Studies is committed to the IZA Guiding Principles of Research Integrity. The authors declare that they have observed these principles.

\section{Acknowledgements}

The process of extending and updating EUROMOD is financially supported by the Directorate General for Employment, Social Affairs and Equal Opportunities of the European Commission [Progress grant no. VS/2008/0318]. We acknowledge the contribution of all past and current members of the EUROMOD consortium and in particular our colleagues at ISER who worked on the development of the version of EUROMOD used in this paper: Paola De Agostini, Francesco Figari, Jekaterina Navicke, Alari Paulus, Olga Rastrigina, Iva Tasseva and Alberto Tumino. The usual disclaimer applies. We are grateful for access to micro-data from the EU Statistics on Incomes and Living Conditions (EU-SILC) made available by Eurostat under contract EU-SILC/2011/55, the Italian version of the EU-SILC (IT-SILC) made available by ISTAT, the Austrian version of the EU-SILC made available by Statistics Austria, the Lithuanian version of the EU-SILC (PGS) made available by the Lithuanian Department of Statistics, the Greek version of EU SILC (PDB) made available by the Greek Statistical Office, the Spanish version of the EU-SILC made available by INE, the Slovak version of the EU-SILC (SK-SILC) made available by the Statistical Office of the Slovak Republic, variables from Bulgarian version of the SILC made available by the National Statistical Institute, variables from the Czech version of SILC made available by the Czech Statistical Office, variables from the Luxembourgish version of SILC made available by CEPS/INSTEAD and STATEC, variables from the Polish version of SILC made available by GUS and the Family Resources Survey (FRS), made available by the UK Department of Work and Pensions (DWP) through the UK Data Archive. Material from the FRS is Crown Copyright and is used with permission. Neither the DWP nor the Data Archive bears any responsibility for the analysis or interpretation of the data reported here. An equivalent disclaimer applies to all other data sources and their respective providers cited in this acknowledgement. Responsible editor: Alan Barrett

Author details

${ }^{1}$ ISER, University of Essex, Wivenhoe Park, CO4 $35 \mathrm{SQ}$ Colchester, UK. ${ }^{2} \mathrm{OECD}$, Colchester, UK.

Received: 2 May 2014 Accepted: 1 September 2014

Published: 27 Nov 2014

\section{References}

Atkinson AB (1980) Horizontal equity and the distribution of the tax burden. In: Aaron HJ, Boskin MJ (eds) The Economics of Taxation. The Brookings Institution, Washington D.C, pp 3-18

Atkinson AB, Rainwater L, Smeeding T (1995) Income Distribution in OECD Countries. Evidence from the Luxembourg Income Study. OECD, Paris

Bergh A (2005) On the counterfactual problem of welfare state research: how can we measure redistribution? Eur Sociol Rev 21(4):345-357

Boadway R, Keen M (2000) Redistribution. Handbook of Income Distribution. In: Atkinson AB, Bourguignon F (eds). North Holland, Amsterdam, pp 677-789

Bourguignon F, Spadaro A (2006) Microsimulation as a tool for evaluating redistribution policies. J Econ Inequal 4(1):77-106 Brady D (2005) The welfare state and relative poverty in rich western democracies, 1967-1997. Soc Forces 88(4):1329-1364 Castles FG, Mitchell D (1992) Identifying welfare state regimes: the links between politics, instruments and outcomes. Governance 5(1):1-26

Decoster A, Van Camp G (2001) Redistributive effects of the shift from personal income taxes to indirect taxes: Belgium 1988-93. Fisc Stud 22(1):79-106

Donaldson D, Weymark JA (1980) A single-parameter generalization of the Gini indices of inequality. J Econ Theory 22(1):67-86 
Duclos J-Y, Araar A (2006) Poverty and Equity: Measurement, Policy and Estimation with DAD. Springer, New York Efron B, Tibshirani RJ (1993) An Introduction to the Bootstrap. Chapman \& Hall, Boca Raton, FL

Esping-Andersen G (1990) The Three Worlds of Welfare Capitalism. Princeton University Press, Princeton

Ferrera M (1996) The 'Southern Model' of welfare in social Europe. J Eur Soc Policy 6(1):17-37

Figari F, Levy H, Sutherland H (2007) Using the EU-SILC for policy simulation: prospects, some limitations and some suggestions. In: Comparative EU statistics on Income and Living Conditions: Issues and Challenges. Eurostat Methodologies and Working Papers, Eurostat, Luxembourg pp 345-374

Figari F, Paulus A, Sutherland H (2015) Microsimulation and Policy Analysis. In: Atkinson AB, Bourguignon F (eds) Handbook of Income Inequality, vol 2. Elsevier, New York

Fuest C, Niehues J, Peichl A (2010) The redistributive effects of tax benefit systems in the enlarged EU. Public Finance Rev 38(4):473-500

Giles DEA (2004) Calculating a standard error for the gini coefficient: some further results. Oxf Bull Econ Stat 66(3):425-433

Hicks A, Swank DH (1984) Governmental redistribution in rich capitalist democracies. Policy Stud J 13(2):265-286

Immervoll H, Levy H, Lietz C, Mantovani D, O'Donoghue C, Sutherland H, Verbist G (2006) Household incomes and redistribution in the European Union: quantifying the equalising properties of taxes and benefits. In: Papadimitriou D (ed) The Distributional Effects of Government Spending and Taxation Palgrave, Houndmills, pp 135-165

Jara HX, Sutherland H (2013) Basline results from the EU27 EUROMOD (2009-2012). In: EUROMOD Working Papers. ISER, Colchester, EM 13/13

Jara HX, Tumino A (2013) Tax-benefit systems, income distribution and work incentives in the European Union. Int J Microsimulation 6(1):27-62

Kakwani NC (1977) Measurement of tax progressivity: an international comparison. Econ J 87(345):71-80

Korpi W (1989) Power, politics, and state autonomy in the development of social citizenship: social rights during sickness in eighteen oecd countries Since 1930. Am Sociol Rev 54(3):309-328

Korpi W, Palme J (1998) The paradox of redistribution and strategies of equality: welfare state institutions, inequality, and poverty in the western countries. Am Sociol Rev 63(5):661-687

Lambert P, Nesbakken R, Thoresen TO (2010) On the meaning and measurement of redistribution in cross-country comparisons. In: Luxembourg Income Study Working Paper Series, vol WP 532

Lerman RI, Yitzhaki S (1985) Income inequality effects by income source: a new approach and applications to the united states. Rev Econ Stat 67(1):151-156

Lietz C, Mantovani D (2007) A Short Introduction to EUROMOD: An Integrated European Tax-Benefit Model. In: Bargain O (ed) Micro-simulation in action: Policy analysis in Europe using EUROMOD. Research in Labor Economics Vol. 25. Emerald, Bingley

Mahler VA, Jesuit DK (2006) Fiscal redistribution in the developed countries: new insights from the Luxembourg Income Study. Soc Econ Rev 4(3):483-511

Myles J (1984) Old age in the welfare state: the political economy of public pensions. Little Brown, Boston

Nelson K (2004) Mechanisms of poverty alleviation: anti-poverty effects of non-means-tested and means-tested benefits in five welfare states. J Eur Soc Policy 14(4):371-390

OECD (2011) Divided We Stand: Why Inequality Keeps Rising. OECD Publishing, Paris

Ogwang T (2000) A convenient method of computing the gini index and its standard error. Oxf Bull Econ Stat 62(1):123-129

Paulus A, Čok M, Figari F, Hegedüs P, Kralik S, Kump N, Lelkes O, Levy H, Lietz C, Mantovani D, Morawski L, Sutherland H, Szivós P, Vðrrk A (2009) The effects of taxes and benefits on income distribution in the enlarged EU. In: Lelkes O, Sutherland $\mathrm{H}$ (eds) Tax and Benefit Policies in the Enlarged Europe: Assessing the Impact with Microsimulation Models. AsssaaaAshgate, Farnham

Paulus A, Sutherland H Tsakloglou P (2010) The distributional impact of in-kind public benefits in European countries. J Policy Administr Manag 29(2):243-266

Piketty T, Saez E (2007) How progressive is the U.S federal tax system? A historical and international perspective. J Econ Perspect 21(1):3-24

Plotnick R (1981) A measure of horizontal inequity. Rev Econ Stat 63(2):481-490

Plotnick R (1984) The redistributive impact of cash transfers. Public Finance Rev 12(1):27-50

Podder N (1993) The disaggregation of the Gini coefficient by factor components and its application to Australia. Rev Income Wealth 39(1):51-61

Reynolds MO, Smolensky E (1977) Public Expenditures, Taxes and the Distribution of Income: The United States, 1950, 1961, 1970Public Expenditures, Taxes and the Distribution of Income: The United States, 1950, 1961, 1970. Academic Press, New York

Sutherland H, Figari F (2013) EUROMOD: the European Union tax-benefit microsimulation model. Int J Microsimulation 6(1):4-26

Verbist G (2004) Redistributive Effects and Progressivity of Taxes: An International Comparison Across the EU Using EUROMOD. In: EUROMOD Working Paper, vol EM 5/04

Wagstaff A, van Doorslaer E (2001) What makes the personal income tax progressive? a comparative analysis of fifteen OECD countries. Int Tax Public Financ 8(3):299-315

Wang C, Caminada K, Goudswaard K (2012) The redistributive effect of social transfer programmes and taxes: A decomposition across countries. Int Soc Secur Rev 65(3):27-48

Yitzhaki S (1983) On an extension of the gini inequality index. Int Econ Rev 24(3):617-628

Yitzhaki S (1991) Calculating jackknife variance estimators for parameters of the gini method. J Bus Econ Stat 9(2):235-239

Yitzhaki S (1998) More than a dozen alternative ways of spelling gini. Res Econ Inequality 8:13-30

10.1186/2193-9012-3-22

Cite this article as: Avram et al: Income redistribution in the European Union. IZA Journal of European Labor Studies 2014, 3:22 